\title{
The International Coal Statistics Data Base
}

\author{
April 1991
}

DISTRIBUTION OF THIS DOCUMENT IS UNLIMITED 


\section{THE INTERNATIONAL COAL STATISTICS DATA BASE}

\section{OPERATIONS GUIDE}

April 1991

Energy Information Administration

Washington, D.C.

\section{MASTER}

DISTRIBUTION OF THIS DOCUMENT IS UNLIMITED<smiles>C1CCCCC1</smiles>

This report was prepared by the Energy Information Administration, the independent statistical and analytical agency within the Department of Energy. The information contained herein should not be construed as advocating or reflecting any policy position of the Department of Energy or any other organization. 


\section{Preface}

The International Coal Statistics Data base (ICSD) is a micro-computer based system which contains information related to international coal trade. This includes coal production, consumption, imports and exports information. The ICSD is a secondary data base, meaning that information contained therein is derived entirely from other primary sources. It uses dBase III+ and Lotus 1-2-3 to locate, report and display data. The system is used for analysis in preparing the Annual Prospects for World Coal Trade (DOE/EIA-0363) publication. The ICSD system is menu driven, and also permits the user who is familiar with dBase and Lotus operations to leave the menu structure to perform independent queries.

Documentation for the ICSD consists of three manuals -- the User's Guide, the Operations Manual and the Program Maintenance Manual. This Operations Manual explains how to install the programs, how to obtain reports on coal trade, what systems requirements apply, and how to update the major data files. It also explains file naming conventions, what each file does, and the programming procedures used to make the system work. The Operations Manual explains how to make the system respond to customized queries. It is organized around the ICSD menu structure and describes what each selection will do. Sample reports and graphs generated from individual menu selections are provided to acquaint the user with the various types of output. 


\title{
The International Coal Statistics Data Base
}

\author{
Operations Guide
}

\author{
Contents
}

Preface $\ldots \ldots \ldots \ldots \ldots \ldots \ldots \ldots \ldots \ldots \ldots \ldots \ldots \ldots \ldots \ldots \ldots \ldots \ldots \ldots \ldots$

1. General Information $\ldots \ldots \ldots \ldots \ldots \ldots \ldots \ldots \ldots \ldots \ldots \ldots \ldots \ldots \ldots$

1.1 Survey Operation Environment and Specird Requirements . . . . . . . . . 1

1.1.a Computer Hardware Used . . . . . . . . . . . . . . . . 1

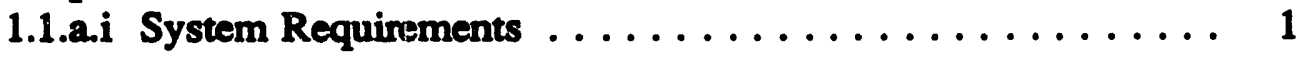

1.1.b Computer Software Used ................... 2

1.1.b.i Required Software ................... 2

1.1.b.ii Operating System and Microprocessors ........... 2

1.1.b.iii Graphics Requirements ................ 3

1.1.b.iv Printing Capabilities $\ldots \ldots \ldots \ldots \ldots \ldots \ldots \ldots \ldots$

1.1.b.v Environment Space $\ldots \ldots \ldots \ldots \ldots \ldots \ldots \ldots \ldots$

1.1.b.vi Installation ..................... 3

1.1.b.vii Operating Procedure $\ldots \ldots \ldots \ldots \ldots \ldots \ldots \ldots$

1.1.b.vii.A System Configuration ............. 6

1.1.b.vii.B Trouble-Shooting Installation Problems . . . . . . 6

1.1.b.vii.C General Usage Conventions . . . . . . . . . 8

1.1.c Special Hardware/Software Requirements ............. 10

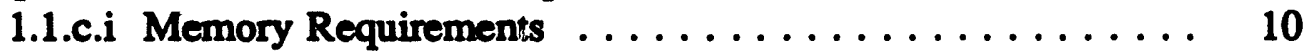

1.1.c.ii Disk Storage . . . . . . . . . . . . . . . . . 11

1.2 Overview of Integrated Manual and Automated Operations . . . . . . . . . 13

1.2.a Integrated Work Flow of Manual and Automated Activities . . . . 13

1.2.b Description of Sequence of Survey Operation Tasks . . . . . . . . . 13

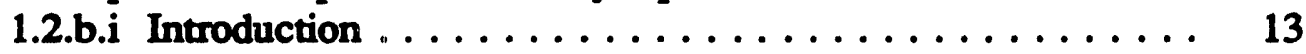

1.2.b.ii Using ICSD Documentation . . . . . . . . . . . 14

1.2.b.iii How to Find Data $\ldots \ldots \ldots \ldots \ldots \ldots \ldots \ldots$

1.2.b.iv Data Types and Sources $\ldots \ldots \ldots \ldots \ldots \ldots$

1.2.b.v Usage Conventions . . . . . . . . . . . . 17

1.2.b.vi Trouble Shooting Guide . . . . . . . . . . . 18

1.2.c Noncomputer Resources and Skill Requirements ..... . . . . . . 19

1.2.d Description of User/Machine Interfaces . . . . . . . . . . . 20 
2. Detailed Information for Each Step of the Data Collection . . . . . . . . . . 20

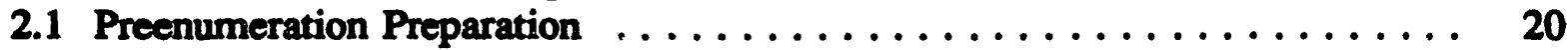

2.1.a Major Frames Updates (Adding/Deleting Respondents) . . . . . . . 20

2.1.b Sample Update/Rotation Procedures . . . . . . . . . . . . . 20

2.1.c Data Collection Forms Mailout ................... 20

2.2 Enumeration ............................... 20

2.2.a Telephone/Personal Interviews .................. 20

2.2.b Data Collection Forms Receipts Controls ............. 21

2.2.c Survey Nonresponse Followups ................. 21

2.2.d Minor Frames Updates (Address/Contact Person Changes) . . . . . 21

2.3 Precomputer Processing . . . . . . . . . . . . . . . . . . 21

2.3.a Data Collection Forms Manual Screening . . . . . . . . . . . 21

2.3.b Data Collection Forms Batching $\ldots \ldots \ldots \ldots \ldots \ldots \ldots \ldots \ldots \ldots$

2.3.c Data Entry . . . . . . . . . . . . . . . . . . 21

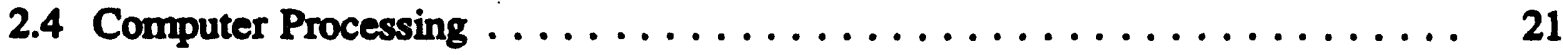

2.4.a Automated Data Edits . . . . . . . . . . . . . . . 21

2.4.b Data Error Corrections ....................... 21

2.4.c Data Adjustments for Item and Unit Nonresponse . . . . . . . . . 21

2.4.d Weighting and Variance Estimations $\ldots \ldots \ldots \ldots \ldots \ldots \ldots \ldots . \ldots \ldots 22$

2.4.e Data Quality Verifications .................... 22

2.4.f Data Tabulation and Presentation of Final Data .......... 22

2.4.f.i Operations and Data Retrieval .............. 24

2.4.f.i.A Main Menu Selections .............. 24

2.4.f.i.B Coal Trade Flows Menu Selections . . . . . . 27

2.4.f.i.C Energy Demand Menu Selections ......... 31

2.4.f.i.D Prices and Freight Rates Menu Selections .... 35

2.4.f.i.E The U.S. Exports ardi Imports Menu Selections . . 38

2.4.f.i.F Options Menu Selections . . . . . . . . . 42

2.4.f.ii Date Sources . . . . . . . . . . . . . . . . . . . 44

2.4.f.ii.A Periods Covered in Data Bases . . . . . . . . . 44

2.4.f.ii.B World Coal Trade .................. 44

2.4.f.ii.C United States Coal Exports and Imports . . . . . 49

2.4.f.ii.D Prices and Freight Rates . . . . . . . . . 50

2.4.f.ii.E Energy Demand ............... 50

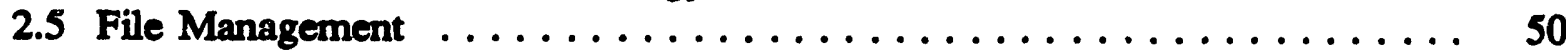

2.5.a Data Security and Confidentiality ............... so

2.5.b Forms Level Master Data File Updates . . . . . . . . . . . . . . . 50

2.5.c Aggregate Level Master Data File Updates . . . . . . . . . . . . . 51

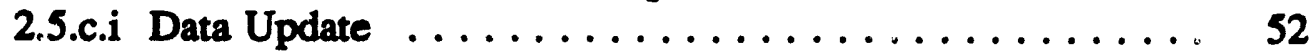

2.5.c.i.A Updating Volumes.Dbf ............ 53

2.5.c.i.B Updating Demand.Dbf . . . . . . . . . . 53

2.5.c.i.C Updating Prices.Dbf and Freight.Dbf . . . . . . 55

2.5.c.i.D Updating the Exports and Imports Data base ... 57

2.5.d Procedures to Declare Data "Final" for a Given Cycle .... . . . 62 
2.5.e Data Revisions ......................... 62

2.5.f Survey Performance Statistics .................. 62

2.5.g Master File Backup and Archiving Procedures ............ 62

Figures

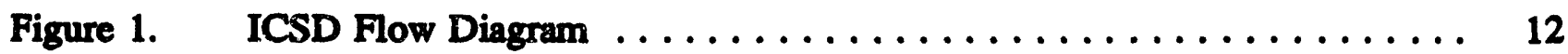

Figure 2. Summary of the ICSD Menu Structure $\ldots \ldots \ldots \ldots \ldots \ldots$

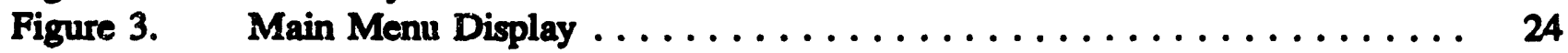

Figure 4. Trade Flows Menu Display $\ldots \ldots \ldots \ldots \ldots \ldots \ldots \ldots \ldots \ldots \ldots \ldots \ldots$

Figure 5. Sample Graph: Time Series View .................. 28

Figure 6. Sample Graph from the Matrix View .................. 28

Figure 7. Sample Graph: Combined View .................... 29

Figure 8. Energy Demand Menu Selections $\ldots \ldots \ldots \ldots \ldots \ldots \ldots \ldots \ldots$

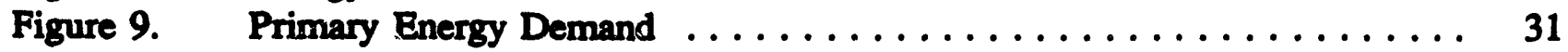

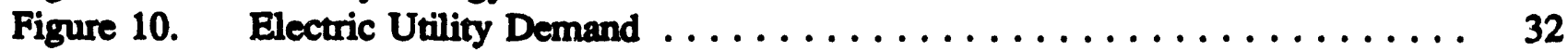

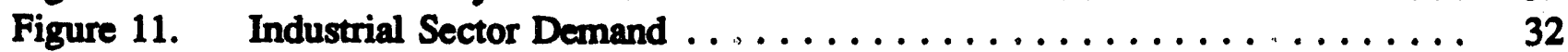

Figure 12. Forecast Sectoral Coal Consumption $\ldots \ldots \ldots \ldots \ldots \ldots \ldots \ldots$

Figure 13. Prices and Freight Rates Menu Display . . . . . . . . . . . . 34

Figure 14. U.S. Imports and Exports Menu Display $\ldots \ldots \ldots \ldots \ldots \ldots \ldots$

Figure 15. Sample US Coal Exports Report $\ldots \ldots \ldots \ldots \ldots \ldots \ldots \ldots \ldots \ldots$

Figure 16. Options Menu Display . . . . . . . . . . . . . . . . 42

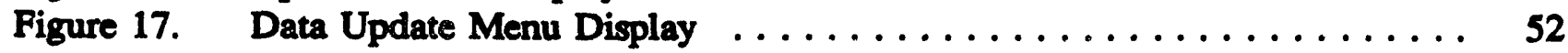




\section{The International Coal Statistics Data base}

\section{Operations Guide}

\section{General Information}

\subsection{Survey Operation Environment and Special Requirements}

The International Coal Statistics Data base (ICSD) organizes data from four separate sources into a querying and reporting system intended for use by coal analysts. It is intended to be run on a microcomputer by users experienced with coal statistics and at least generally familiar with Lotus 1-2-3 and dBase III+.

\section{1.a Computer Hardware Used}

Any microcomputer compatible with the IBM PC may be used. A hard disk with at least 8 megabytes of free space is required. As the ICSD requires virtually all system memory after DOS is loaded, at least 640 kilobytes of RAM is required.

\section{1.a.i System Requirements}

The ICSD is intended to be used on IBM-compatible microcomputers capable of running Lotus 1-2-3 and dBase $\mathrm{II}+$. Both Lotus and dBase must be present and accessible by the ICSD system. Because of the size of the component data bases and the use of DOS command shells to load different programs in memory, relatively unusual demands are placed on the system, both in terms of available disk storage space and memory. The ICSD system will run on many microcomputer systems, provided adequate fixed disk storage is available and the computer comes equipped with and has available the full 640 kilobytes of random access memory.

A hard drive is required to store ICSD programs. Approximately 8 megabytes of storage must be free before installing the program.

A disk drive capable of reading the $51 / 4$ inch, 1.2 megabyte floppies supplied with the ICSD must be available. This can be a standard AT high density drive. 


\section{1.b Computer Software Used}

\section{1.b.i Required Software}

DOS

PK-UNZIP

LOTUS 1-2-3

DBASE III PLUS
The ICSD was developed using MS-DOS varsion 3.31. Therefore, the ICSD should also operate under that or any higher version of MS-DOS.

Installation is accomplished using the software routine PK-UNZIP. A copy of the "EXE" module for PK-UNZIP is contained on diskette 1.

Version 2.01 or 2.2 must be used rather than Version 1 or 1.A. All of the worksheets used by the ICSD contain macros that are not compatible with earlier versions of Lotus. If Lotus 2.2 will be used, a memory manager must be used to ensure that there is enough room in low memory to load the ICSD worksheets (particularly D1.Wk1)
Either release of dBase III + may be used, and while not tested, it is likely that dBase III + will also work. DBase II will not work, nor will dBase IV (because there won't be enough memory to load Lotus). A Config.db file is supplied by the ICSD.

\section{1.b.ii Operating System and Microprocessors}

Any version of DOS after 3.0 can be used. The ICSD system assumes that certain DOS commands will always be available, such as the external command BACKUP. This means that the subdirectory holding the user's DOS programs must be in the current path, as must the user's Lotus and dBase files. If this is not the case, either issue the DOS command PATH = with appropriate directory listed or consult the DOS operating manual for more information on how your system is set up if these concepts are unfamiliar.

There are no separate microprocessor requirements beyond those required to operate Lotus 12-3 and dBase III. Presumably, any system configured with the Intel $8088,8086,80286$ or 80386 , or the NEC V20 and V30 will do provided that the system will run those two programs without problems. 


\section{1.b.iii Graphics Requirements}

The ICSD makes full use of Lotus graphics capabilities to illustrate the trends in world coal trade and permit data relationships to be analyzed visually. But just as Lotus 1-2-3 can be run on systems without a graphics card of any kind, the ICSD also does not require that graphics capabilities be present. However, they are highly recommended, particularly color graphics. The ICSD will use whatever graphics drivers were installed with Lotus 1-2-3, and no adaptation is nezded.

\section{1.b.iv Printing Capabilities}

Many printed reports may be generated on the ICSD but it is not required that a printer be available. If one is, it should be capable of printing on at least 130 positions per line and have a compressed mode available. The ICSD includes a miscellaneous option for sending a set-up string to the printer to invoked compressed printing.

The same applies to graphics printing. It is not necessary to have a graphics printer, but if one is available, the Lotus 1-2-3 program for printing graphs may be used to print the graphs generated while using the ICSD. Any printer supported by Lotus 1-2-3 will work.

\section{1.b.v Environment Space}

DOS provides a special area of memory set aside for "the environment" where certain variables, otherwise meaningless to DOS, may be stored for access by programs. The ICSD makes use of this facility to keep track of the location of the Lotus and dBase program files. On some systems and in some versions of DOS the amount of environment space is limited to 128 bytes and may already be in use by other programs. While the ICSD's environment requirements are limited to specifying two paths which are removed from the environment upon program completion, and most users will not have to be concerned with this parameter, it is possible that some users may receive an error message warming of too little environment space. If this occurs, remove unnecessary SET commands and try again, remembering not to load terminate-and-stay-resident programs before or while using the ICSD system. Alternately, run the ICSD with the RESET parameter, which will reboot the system with only the bare minimum of drivers required to operate the system. The instailation program will indicate whether sufficient environment space is present.

\section{1.b.vi Installation}

Installation of the ICSD is relatively simple. There are three mandatory steps and an optional fourth step:

1. Note Directory Information Make a note of the location of where the Lotus, $d B a s e$ and DOS files are stored before running the installation program. Use the DOS SET 
command to get the path information. Also make certain that the dBase and Lotus files are in the current path. If this is not the case, issue the DOS command PATH= with the appropriate directory listing. If using Lotus 1-2-3 version 2.2 , also note whether the system uses a memory manager. The noted information will be used by the installation program.

2. Run the Installation Program Insert the ICSD INSTALL DISK (ICSD91-1) in drive A. Then type A: and enter INSTALL. Usually, the $51 / 4^{\prime \prime}$ floppy drive will be A: and it is in this drive that the INSTALL DISK should be placed.

Example:

$$
\begin{array}{ll}
\text { A: } & \text { <enter > } \\
\text { INSTALL } & \text { <enter > }
\end{array}
$$

The installation program reads various system parameters to ensure that there is enough room for the ICSD, enough memory, and so forth, and then (a) uses PKWARE's UNZIP program to copy all files to the location specified by the user; and (b) writes a brief batch file in the system's root directory of the C: drive, C:IICSD.BAT, to be used to start the program.

The program will request that both of the two numbered disks be inserted in turn to send the files to the user's system.

3. Startine Program Start the ICSD by entering ICSD at the C: prompt. The ICSD batch file is initially placed in the root directory of drive C: by the installation program, but it may be moved to any location in the system's path. Depending on system capabilities, it may be necessary to call ICSD.BAT with the RESET parameter (i.e. entering ICSD RESET from the DOS prompt). This will be necessary if the system, as currently configured, does not have enough "low" memory to run the ICSD but could have enough if unnecessary programs were required. If this condition exists on the user's system, it will be identified at the end of the installation program.

It will be necessary to start ICSD by entering ICSD RESET if Lotus version 2.2 along with a memory manager is used.

Example: Depending on how much memory is available and the results of the installation process, use either:

C:IICSD or

C: UICSD RESET 
The difference between starting without the RESET parameter and with concerns whether the system will first be rebooted to remove superfluous drivers, resident programs, and the like. Starting with the RESET parameter is optional for systems with free low memory in excess of 350,000 bytes with dBase III loaded. Otherwise it is mandatory. If RESET is used, the system will be restored to its original configuration upon completion of the ICSD. If not, the ICSD will be called with the current amount of memory and existing system drivers. In order for the original settings to be restored, the ICSD menu system must be used to exit the program (i.e. do not just turn the system off). If the original configuration is not restored for this or some other reason, enter the command C:IICSD RESTORE.

In either case, dBase III must be in the system's path.

Note that vefore the opening ICSD menu appears, the dBase licensing screen will come up. This screen is built into dBase. Either press enter once or wait several seconds for it to disappear.

4. Backup directory The ICSD has an OPTIONAL facility that restores copies of the original files in case data becomes corrupted through user errors. This requires that another 6 megabytes of disk space be available. Accordingly, use of this capability is only recommended for users with large amounts of free disk space and little knowledge of data base procedures.

The directory to hold the backups should be created with the DOS MD command using a directory name and path chosen by the user (e.g. MD C:IBACKUP). ICSD files should then be copied to that directory (e.g. COPY C:IICSDI*.* C:(BACKUP). The name of the directory used is requested during installation for users who require data security. 


\section{1.b.vii Operating Procedure}

\section{1.b.vii.A System Configuration}

Since the ICSD relies on Lotus and dBase, it is important that Lotus, in particular, be installed correctly for the system it is on. Most dBase configuration is handled by the ICSD and no additional parameters need be supplied. A special Config.db file is provided with the other ICSD files and user's familiar with dBase configuration settings may edit to customize

Configuration of Lotus 1-2-3 is handled by both the Lotus installation menu choice called Install when Lotus is first started, and from the Worksheet Global Default command once a worksheet is loaded. The former is used to select text and graphics printers and type of screen outpus. The latter establishes default settings. There are only a few mandatory default Lotus settings for the ICSD:

- The default directory must be set to the same directory that holds the Lotus 12-3 program files (e.g. 123.com or 123.exe). This means that if the Lotus program files, such as $123 . c 0 m$ are in C:Lotus, then Lotus must be configured by use of the /Worksheet Global Default Directory command so the initial directory is also C: Lotus.

- The default printer must be set for a wide-margin, preferably with a set-up string that tums on compressed print if that feature is available. On many printers this is 027015 . If graphs are to be printed, the settings on the Print Graph program inay be changed so that the directory where the program looks for graphs to print is properly set for C:VCSD. While configuration of dBase III is not required, the same considerations apply to most printed reports. It is possible to send set-up strings to the printer from within the ICSD by using Miscellaneous Option 5.'

\section{1.b.vii.B Trouble-Shooting Installation Problems}

If the ICSD INSTALL program does not work properly, check the following:

Problem

No dBase intro screen

\section{Check}

Check whether dBase is in the path using the DOS SET command. If not, insert it.

1. This option includes both start-up strings for standard printers as well as the codes required to print Laserjet II reports in line printer type, landscape format. 
dBase intro screen but nothing more

No files are copied

ICSD.BAT used to start program but nothing happens

dBase error message appears during installation (Cancel, Ignore, Suspend)

System configuration problems
Check whether default drive was set for the ICSD installation disk. If this is drive A, enter the DOS command

$$
\text { A: <enter > }
$$

before typing INSTALL <enter >.

This should not occur. However, anything is possible, and if it does happen, contact the database distributor and request technical assistance from the ICSD database administrator.

Check for existence of C:UCSD.BAT. If it isn't present, rerun installation program.

Select Cancel, type QUIT, rerun installation program

Run the batch program, ICSD RESTORE, to return to original configuration. If this fails, manually copy the files AUTOEXEC.OLD to AUTOEXEC.BAT and CONFIG.OLD to CONFIG.SYS.

If the ICSD does not function properly, check the following:

No ICSD screen

Rerun the installation program, first being sure that dBase is in the path. If it is, try giving the command

$$
\text { _ICSD C:IDBASE C:ILOTUS }
$$

This command MUST be given from inside the ICSD directory. Substitute the correct directory names for $\mathrm{dBase}$ and Lotus instead of those in the example. 
Not enough environment space

Not enough memory

Lotus won't run

1-2-3 works with ICSD but other uses always result in ICSD files being loaded and run

No dBase screen
First thy running with the ICSD RESET parameter. If still not enough, consult the DOS manual about inseriting a SHELL sommand in the VCSDVONFIG.ICS file, then retrying the ICSD RESET program.

If this error message appears while the ICSD is using Lotus, use a memory manager to increase the size of the worksheet that can be loaded. Rerun the Installation program and select choice under memory managers.

Be sure information supplied on location of Lotus files during installation is correct. If so, load 1-2-3, select Worksheet /Global /Status Directory. Insert the name of the Lotus directory as the initial directory, / Update the Lotus configuration information, and retry.

This condition occurs if the system is tunned off before exiting the ICSD using the ICSD menu system. Run the ICSD batch program with the RESTORE parameter. If that doesn't work, erase the file AUTO123.WK1 from the Lotus directory.

Check correctness of dBase location specified during installation. Check if dBase will run independently. If so, load dBase from the ICSD directory, issue command DO MASTER from dBase prompt. If this works, rerun installation be issue CTRL + BREAK before restoring files again and exit from Install batch program. If not, check to see if Master.Prg is present in ICSD directory and rerun complete installation if it isn't.

\section{1.b.vii.C General Usage Conventions}

I) Lotus and dBase

The ICSD allows users a wide range of choices, both to perform significant anaiysis within a menu-driven system, and to fashion custom queries from within and without the menu system for those users familiar with Lotus and dBase operations. This is done by design to encourage flexibility and to make the system as useful as possible to those already familiar with $\mathrm{dB}$ ase and Lotus conventions. However, this flexibility is provided at the possible expense of file security and possible jeopardy to program operation. That is, the user may request to continue working with data from the dBase command prompt level, or inside a
worksheet free from macro control. In the former case, the dot prompt level is invoked with 
a data base (and, in some cases, associated indexes) in use. A careless retum to the ICSD menu system could leave open data bases when they shouldn't be, which could interfere with the proper functioning of the prepared programs. To avoid these problems, users wishing to take advantage of ICSD flexibility should note the following general rules and escape conventions:

While in a dBase environment:

F10 - Closes any open filter files, closes data bases and restarts the controlling menu program, MASTER.PRG.

DO MASTER - restarts the system, but does not close open files.

RESUME - if issued after being in the ICSD system, will return to the system, which will then close open files. The on-screen instructions that appear before being dropped to the dot prompt level explain what is required to return.

QUIT - This dBase command will close files and avoid possible file corruption, but is less preferable than returning via the menu systeni.

ESCAPE - is usually permitted except during operations, such as reindexing, where files would be damaged if the operation were interrupted. Escape will cause a return to the previous menu level, except from the dot prompt.

ERROR - if a dBase error message is given, first try to Ignore it, but if error messages recur, cancel and hit F10.

\section{While in a Lotus environment:}

MENUS - all Lotus main menus have common elements: Report, Print, and Graph to invoke the respective functions. After selecting Report from any Lotus menu, the cell pointer is positioned on the reported data and the user is free to move it elsewhere to see other sections of the report. To return to the menus, hit enter several times.

ALT M - returns to the ICSD worksheet menu system.

/QY - retums to the ICSD dBase menu system. While the transition is usually smooth, for some of the larger worksheets, like that for the first demand choice, it may be unpredictable depending on the operations performed while in the worksheet. This means that if the ICSD menus are not reloaded, the F10 command should be given to restart. On versions of Lotus later than 2.01 , it may be necessary to use /QYY to leave the worksheet.

ALT I - goes to ICSD program macros. 
CTRL + BREAK - Escapes from the ICSD worksheet menu system. This is less desirable that selecting the "Free" menu choice.

It is important to be familiar with these commands before escaping from the ICSD menu system. This manual does not cover Lotus or dBase operation outside of the ICSD menu system. Many very powerful types of analysis are possible, and open access means that each data telement may be found, but it is necessary to consult the users guides to those programs for further information.

\section{II) File Names}

As the ICSD uses more than a hundred files, certain ruies had to be devised to identify them. These are fully described in the Program Maintenance Manual. Each of the submenus bears a single letter in parentheses in the lower-right hand comer. That letter will supply the first letter of the files associated with that menu. The second character of each of the operational files will be a number corresponding to the number of the menu selection that uses that program or file. File extensions adhere to the general dBase conventions described in the dBase manual (e.g. a file ending in .frm is a report form, a file ending in $n d x$ is an index, and so on.). An on-line explanation of the function of each file is always available through the fourth choice from the Options Menu.

\section{III) Background Colors}

The background color visible on color monitors also follows a convention. The master menu has a blue-green background, each submenu has a red background, and subsequent operations take place against a solid colored background. The purpose of this scheme is only to give the user some sense of location in the menu tree from a non-obtrusive visual clue. These color schemes will not be visible on monochrome monitors.

\section{1.c Special Hardware/Software Requirements}

\section{1.c.i Memory Requirements}

The ICSD system first loads $\mathrm{dBase}$ III, which requires a minimum of $256 \mathrm{~K}$ bytes and operates better with at least $320 \mathrm{~K}$ bytes, and then loads Lotus 1-2-3, requiring on the order of another $200 \mathrm{~K}$ bytes. Lotus will in turn load wor'sheets requiring a further $80 \mathrm{~K}$ bytes. For this reason, the ICSD is really intended for use on systems having a full $640 \mathrm{~K}$ bytes of RAM, and ideally a memory manager and a version of Lotus that can load worksheets into high memory. For the same reason, no terminate and stay resident programs (such as Sidekick) should be present when the ICSD is being used. Experiments have shown that somewhat less memory may be available without hampering ICSD operation, but it is better 
to use the full $610 \mathrm{~K}$ DOS address space. The Install.Bat program determines whether the system is capable of running ICSD.

\section{1.c.ii Disk Storage}

The files that are supplied with the ICSD require approximately 8 megabytes of fixed disk storage space. It is not feasible to run the system from floppy disk drives. An option included with the systern is to set aside other areas of the fixed disk as a storage area for backup copies of key data and program files. This option, which is possible but not usually recommended for experienced users, takes up an additional 7.8 megabytes. The system's files must be stored in a subdirectory of any drive called ICSD. The backup files may be stored on another drive in any sutidirectory. 


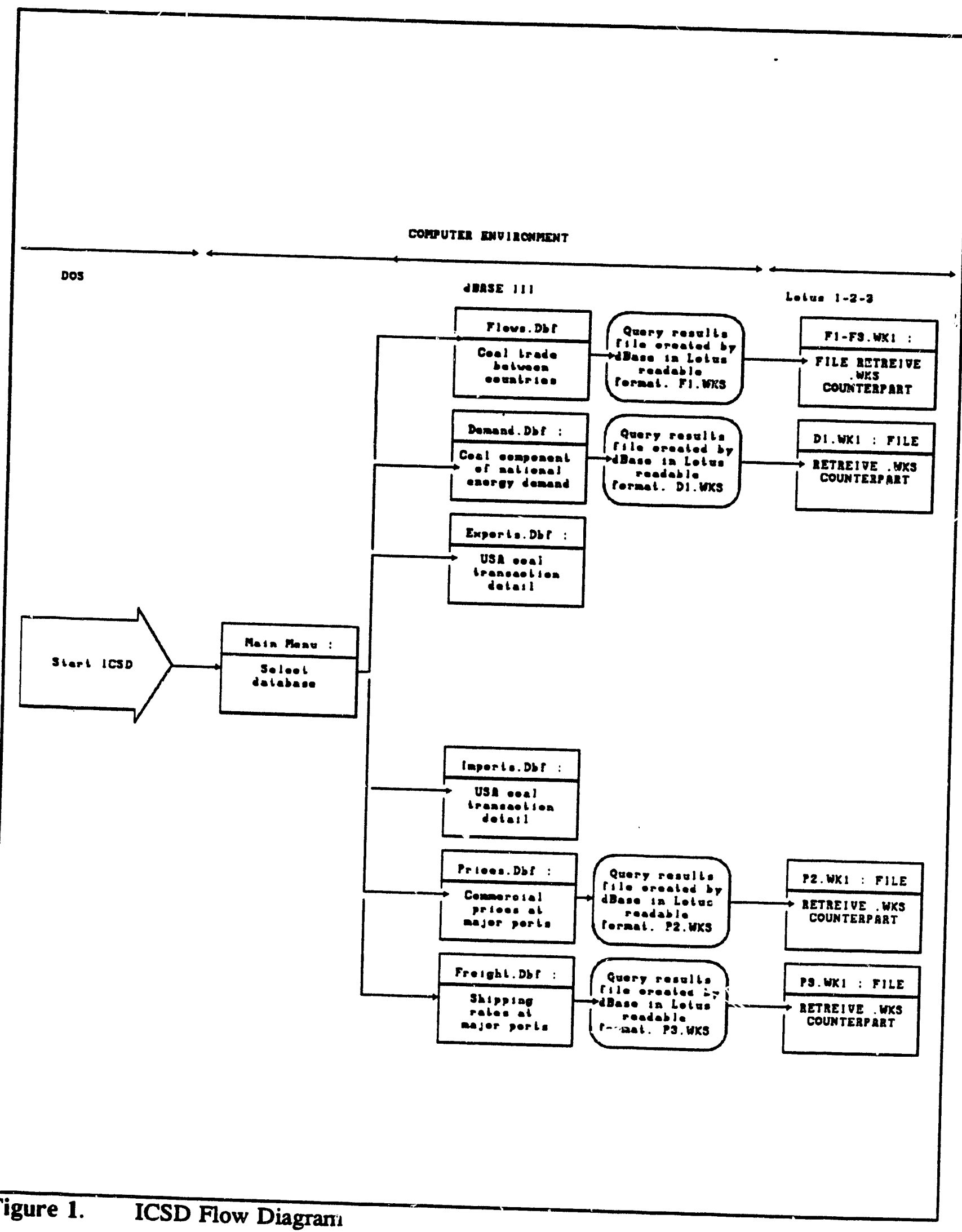




\subsection{Overview of Integrated Manual and Automated Operations}

\section{2.a Integrated Work Flow of Manual and Automaied Activities}

This manual is organized so to follow the sequence of menu screens shown to ICSD users. The next section describes the types of data stored in the ICSD and how it may be accessed. 1.2.b Description of Sequence of Survey Operation Tasks

\section{2.b.i Introduction}

The International Coal Statistics Data Base (ICSD) presents four types of data: (1) the quantity of coal traded between importers and exporters, (2) the price of particular types of coal and the cost of shipping it in world trade, (3) a detailed look at coal shipments entering and leaving the United States; and (4) the context for world coal trade in the form of data on how industrial economies use coal and other primary energy sources, and how usage is projected to change in the future. This information is stored in a microcomputer-based system that uses $\mathrm{dB}$ ase $\mathrm{II}$ and Lotus 1-2-3 to locate, report and display data. The system is menu driven, but permits user's familiar with $\mathrm{dBase}$ and Lotus operations to leave the menu structure to perform independent queries or analysis. On the other hand, special knowledge of either Lotus or $\mathrm{dBase}$ III is not required. It operates by using dBase for the menu system, operating programs and data storage and makes automatic transitions into Lotus whenever spreadsheet capabilities or graphics are needed.

The menu system is organized around the four types of data mentioned above. A user need only understand what the four types of data are and which may be needed to respond to a query in order to make the initial selection from the main menu. The initial menu selection will lead to a submenu of procedures for querying that type of data, followed by programs that interactively select and display responsive data. On-line help is available in thi form of a pop-up screen that briefly explains each menu selection. All operations begin and exi ai

In addition to the four menu choices corresponding to major data types, there is a fifth choice from the main menu that controls access to various system maintenance programs. The only system maintenance program that must be run is the first, which configures the ICSD system by requesting whether the backup option will be used, and, if so, where the backup file copies will be kept. Other system maintenance options include routines to rebuild index files in case of a malfunction, an annotated file list explaining the purpose of existing files and allowing newly created files to be noted, and a program to either copy files or restore corrupted files to their original contents. There is also a further sub-menu of miscellaneous programs that perform various non-routine operations, including some file update procedures, DOS shells, blank Lotus worksheets, printer set-up, and so forth. 


\section{2.b.ii Using ICSD Documentation}

The Operations Manual follows the actual menu structure used by the program. Any question about what a certain component of the program does may be answered by noting the item.

\section{2.b.iii How to Find Data}

What types of coal-related queries can be made? The following listing is provided as an introduction to the menu system. For each query type, a reference to the menu and selection number that would find this data is given in italics. A complete explanation of the menu system begins in Section 2.4.f.i., Operations \& Data Retrieval.

- The total volume exported by a country or region for a specified coal type in a specified year or series of years in user-specified units.

Flows, Choice 1

The total volume imporied by a country or region for a specified coal type in a specified year or series of years in user-specified units.

Flows, Choice 2

- The percent share that a particular country's imports represented of a given coal exporter's exports for a user-specified coal type and a user-specified year.

Flows, Choice 2 
- The percent share that a particular country's exports represented of a given coal importer's imports for a user-specified coal type during a user specified
period.

\section{Flows, Choice 2}

- A comparative time series of imported volumes by coal type for any two to six importing countries or regions from either all exporters or a single coal
exporter.

Flows, Choice 3

The volume, coal type, transaction value and unit cost of coal leaving a U.S. port or region for any foreign country between 1980 and mid-1990.

\section{Exports \& Imports, Choices 1 \& 2}

- The volume, coal type, transaction value and unit cost of coal shipped to the U.S. from any foreign country between 1980 and mid 1990.

Exports \& Imports, Choices 1 \& 3

- Representative end of quarter prices and shipping rates for coal loads leaving domestic and foreign ports, broken down by vessel size, sulphur, heat content and probable destination.

\section{Prices \& Rates, Choices 1 \& 2}

Prices and rates averaged for user specified periods broken down by vessel
size.

\section{Prices \& Rates, Choices 1 \& 3}

- The projected coal balance of major industrial economies through the year 2010 , as well as the importance of coal as a primary fuel for all economic sectors, end-users, and the industrial and electric utility sectors.

Demand, Choice 1 
Each of the four data types is associated with a menu selection from the master menu. When chosen, a submenu is loaded, which controls further user options. Each submenu contains a final selection to retum to the master menu. Each submenu in tum loads a program to accomplish the selected task. Many of these programs also offer a possible way to return to the menu system in case selection of that component program was made in error, and will return to the menu system after execution in any case. Many component programs perform a portion of their function in $\mathrm{dB}$ ase and then load Lotus to analyze query results. With only a few exceptions, once in a Lotus worksheet, a light-bar type menu system similar to the familiar Lotus menu, is used to guide the user through program decision points and to aid in preparing reports and graphics.

The existence of the system of menus does not mean that every option is govemed by preestablished selections. The user is free to leave either the dBase menu structure or the Lotus menus whenever independent analysis appears desirable. To make use of this option, it is necessary to be familiar with the general usage conventions described in 1.2.b.v.

\section{2.b.iv Data Types and Sources}

The ICSD contains four types of data: (1) official EIA statistics on how much coal exporters sold to importers between 1980 and 1989 for both steam and metallurgical grades; (2) a representative sampling of quarterly coal prices and ocean freight rates taken from commercial sources; ${ }^{2}(3)$ detailed Bureau of the Census records of coal shipments to and from the United States; and (4) data and projections on how coal and other primary fuels are used in the major industrial economies, taken from a study of future coal imports and energy usage prepared by SRI Technology for EIA. ${ }^{3}$ Detailed information on the exact sources of all data appearing in the ICSD is provided in section III (Data Sources).

\footnotetext{
${ }^{2}$ Since this information is derived from a private data series in a copyrighted publication, it is not available on copies of the ICSD that are not for government use. 3The sources for these data are as follows: (1) Energy Information Administration, Arcnual
Prospects for World Coal Trade, 1989 and earlier editions; (2) McGraw-Hill, Coal Week
International, "World Scan," down International, "World Scan," downloaded and reformatted from Nexis computerized database, end of quarter issues, 1980 - 1990; (3) EIA mainframe computer data sets supplied by the US. Customs Department.PRJ.EM522.IMEX(EXPORT), which contain data (exports) and modified to protect proprietaryt gathered on Forms IM145 (imports) and EM522 and treatment given these data by EIA seery data. For a discussion of the inherent limitations the Bureau of the Census publi Inc.
} 


\section{2.b.v Usage Conventions}

The ICSD allows users a wide range of choices, both to access data from within a menudriven system, and to fashion custom queries from within and without the menu system. This is done by design to encourage flexibility and to make the system as useful as possible to those already familiar with $\mathrm{dBase}$ and Lotus conventions. No experience with either program is required; the ICSD menu structure will provide an overview of the world coal trade and particular aspects of interest to the user through the menu system alone. But as not every possible type of query may be anticipated in advance, the ICSD permits users familiar with Lotus and dBase query and reporting capabilities to take control of the data bases. In the case of the $\mathrm{dBase}$ environment, this is referred to as the dot prompt level, as that is where dBase commands are given. In the Lotus environment, the CMD light at the bottom of the screen is off and movement of the cell pointer is left unrestricted.

However, this flexibility is provided at the possible expense of file security and possible jeopardy to program operation. For example, a user may continue working with data from the dBase command prompt level when the dot prompt level is invoked with a data base (and, in some cases, associated indexes) in use. A careless retum from the dot prompt to the ICSD menu system could leave data bases open which could interfere with the proper functioning of the prepared programs or cause an error missage to appear. Particular care should be taken to close files, and update associated indexes if the data in particular tables is changed by the user without opening the index. A listing of many Lotus and dBase commands applicable to direct data base access is found in the trouble-shooting guide section. The user should be familiar with these commands before escaping from the ICSD menu system. Further information may be found in either the Lotus 1-2-3 or dBase operating
manuals. 


\section{2.b.vi Trouble-Shooting Guide}

While in a dBase environment:

F10

Closes any open filter files, closes data bases and restarts the ICSD
system

DO MASTER Restarts the system, but does not close open files

RESUME If issued after being in the ICSD system, will retum to the system, which will then close open files. The on-screen instructions that appear before being dropped to the dot prompt level explain what is required to
return.

QUTT

ESCAPE

ERROR

This dBase command will close files and avoid possible file corruption, but is less preferable than retuming via the menu system.

Is usually permitted except during operations, such as reindexing, where files would be damaged if the operation were interrupted. Escape will cause a retum to the previous menu level

If a dBase error message is given, first try to ignore it, but if error messages recur, cancel and hit F10.

While in a Lotus environment

MENUS

All Lotus main menus have common elements: Report, Print, and Graph to invoke the respective functions. After selecting Report from any Lotus menu, the cell pointer is positioned on the reported data and the user is free to move it elsewhere to see other sections of the report. To retum to the menus, hit enter several times.

ALT M Returns to the ICSD worksheet menu system.

/QYY

Returns to the ICSD dBase menu system. While the transition is usually smooth, for some of the larger worksheets, like that for the first demand choice, may be unpredictable depending on the operations performed while in the worksheet. This means that if the ICSD menus are not reloaded, the DO MASTER command should be given.

ALT I Moves the Lotus cell pointer to ICSD program macros 
Refer also to the similar guide in the description of installation procedure for trouble-shooting
installation problems.

\section{2.c Noncomputer Resources and Skill Requirements}

Personnel accessing the ICSD system fall into three categories: the ICSD user, the ICSD program maintenance person, and the ICSD data editor. The following skill requirements
have been identified:

(1) There are no special skill requirements or araining needed for the typical user of the ICSD. The system is menu driven and organized around the four types of data explained in Section 1.2.b.iv. A user nend only understand what the four types of dara are and which may be needed to respond to a query in order to make the initial selection from the main menu. The initial menu selection will lead to a submenu of procedures for querying that type of data, followed by programs that interacti ely select and display responsive data. On-line help is available in the form of a pop-up screen that briefly explains each menu selection. All operations begin and end at the main menu. Users familiar with Dbase and Lotus operations may leave the menu structure to perform independent queries or analysis. On the other hand, specialized knowledge of either Lotus or dBase III is not required.

(2) The program maintenance person requires a knowledge of dBase computer programming and Lotus macro programming. Also, the person should take refresher courses annually in these languages. She/he is required to make program revisions whenever a new year's data is added to the system. For the most part these are simple and are noted in program comments by ** UPDATE NOTE. A typical instance would be to edit a statement that establishes a range of possible years to be queried, say from 1980 to 1989 , and put the new outer bound of the range after data for 1990 have been added. The programs that require this limited type of editing are (each has
the extension .PRG):

\section{$\begin{array}{lllllllll}\text { D1 } & \text { E2 } & \text { E3 } & \text { F1 } & \text { F2 } & \text { O56B } & \text { P2 } & \text { P3 } & \text { UV1 }\end{array}$}

Other program changes, such as the programming needed to accommodate changes to table structure when a new year is added, are more difficult and require familiarity with dBase computer programming and Lotus macros.

(3) The data editor needs skills that fall into two categories: (a) the ability to use the ICSD update programs, and (b) familiarity with dBase progranming and SuperWylbur macros on the EIA mainframe. The data editor will receive on-the-job training in editing the ICSD update programs and will be required to take courses in dBase programming and Superwylbur macros. Training will be scheduled annually for the data editor. Some ICSD data bases, such as Prices.dbf and Freight.Dbf are updated manually using data in hardcopy form. These are updated by accessing the ICSD 
update program menu. No special data skills are required. In theory, other more complex data bases, such as Demand.dbf can be updated by following the instructions given in the menuing system. But, in reality, this depends on the new year's data being supplied by the Intemational Energy Agency in precisely the same format as that for the previous year. While this is possible, it is not likely. Corresponding changes to the programs named UDMDx.PRG (where $x$ is a number from 1 to 9) may have to be made to accommodate changes. Data editing also requires at least some familiarity with Superwylbur operations on the mainframe, and knowledge of either microcomputer communication programs, or file transfer procedures over the EIA local area network.

\section{2.d Description of User/Machine Interfaces}

The only interface is the microcomputer keyboard and screen. However, downioading the original data for U.S. coal imports and exports reçuires access to the EIA mainframe
computer.

\section{Detailed Information for Each Step of the Data Collection}

\subsection{Preenumeration Preparation}

In each instance the ICSD uses data that has already been processed by other analysts and does not require any user surveys, telephone interviews, data collection forms, survey nonresponse followups and the like. It is not unpiocessed primary data but secondary factual data collected and reported from other public and private sources (see description of data sources in section 2.4.f.ii). References to these topics are included in the table of contents and below in response to the required documentation standards set forth in EIA Standard 88-

\section{1.a Major Frames Updates (Adding/Deleting Respondents)}

Please refer to the discussion under section 2.1 .

\section{1.b Sample Update/Rotation Procedures}

Please refer to the discussion under section 2.1.

\section{1.c Data Collection Forms Mailout}

Please refer to the discussion under section 2.1.

\subsection{Enumeration}


Please refer to the discussion under section 2.1.

\section{2.a Telephone/Personal Interviews}

Please refer to the discussion under section 2.1.

2.2.b Data Collectior. Forms Receipts Controls

Please refer to the discussiun urider section 2.1 .

2.2.c Survey Nonresponse Followups

Please refer to the discussion under section 2.1.

2.2.d Minor Frames Updates (Address/Contact Person Changes)

Please refer to the discussion under section 2.1.

\subsection{Precomputer Processing}

Please refer to the discussion under section 2.1.

\section{3.a Data Collection Forms Manual Screening}

Please refer to ths discussion under section 2.1.

\section{3.b Data Collection Forms Batching}

Please refer to the discussion under section 2.1.

\section{3.c Data Enitry}

Please refer to the discussion under section 2.1. Data entry for update purposes is described in 2.5.c and following sections.

\subsection{Computer Processing}

Please refer to the discussion under section 2.1. Computer processing of updated câta is discussed in 2.5.c and following sections.

\section{4.a Automated Data Edits}

Please refer to the discussion under section 2.1. 


\section{4.b Data Error Corrections}

Please refer: 0 the discussion under section 2.1 .

\section{2,4.c Data Adjustments for Item and Unit Nonresponse}

Please refer to the discussion under section 2.1.

\section{4.d Weighting and Variance Estimations}

Please refer to the discussion under section 2.1.

\section{4.e Data Quality Verifications}

The ICSD relies on the validity of the primary data sources and does not independently verify manually, such as the update of the prices and the update process where data is entered for the anaiyst to double check ber/s is and freight rates data bases, the only verification is

\section{1.f Data Tabulation and Presentation of Final Data}

Data tabulation takes place in either of two ways. First, the main ICSD programs use the programming commands of dBase III to sum or average individuai data items to be reported. printer, to an reports generated file, to a Lotus worksheet or to a dBase data base. This applies to the bases. Second, data tabulation occurs ind data bases and the price and freight rates data first using $\mathrm{dBase}$ tc prepare a special in preprogrammed Lotus worksheets. This is done by cenverted by dBase to a format readable holding the requested data subset, which is - data, and then referred to in the formuble by Lotus, loaded into the Lotus worksheet as raw .- data, and then referred to in the formulas used in other sections of the worksheet. 


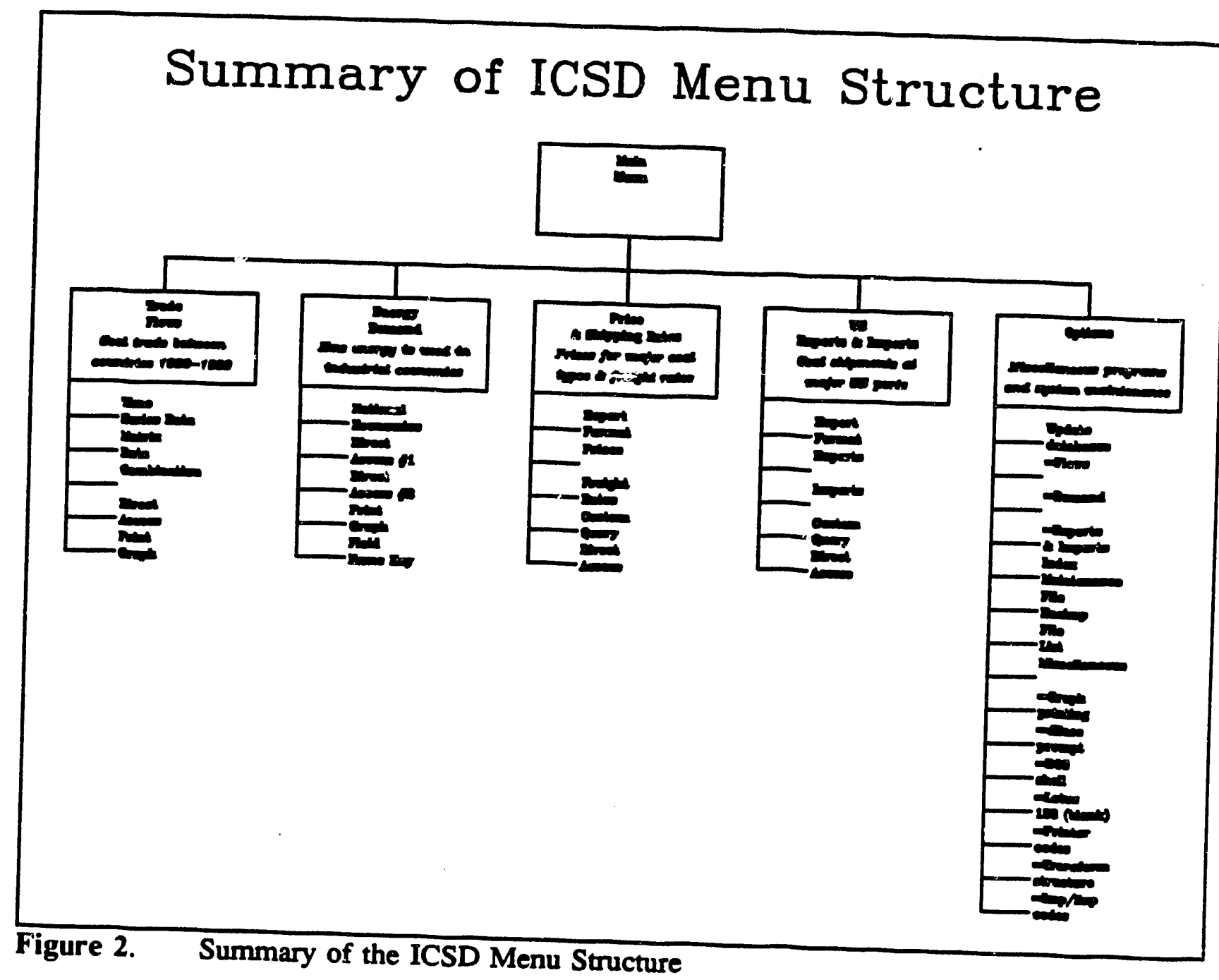




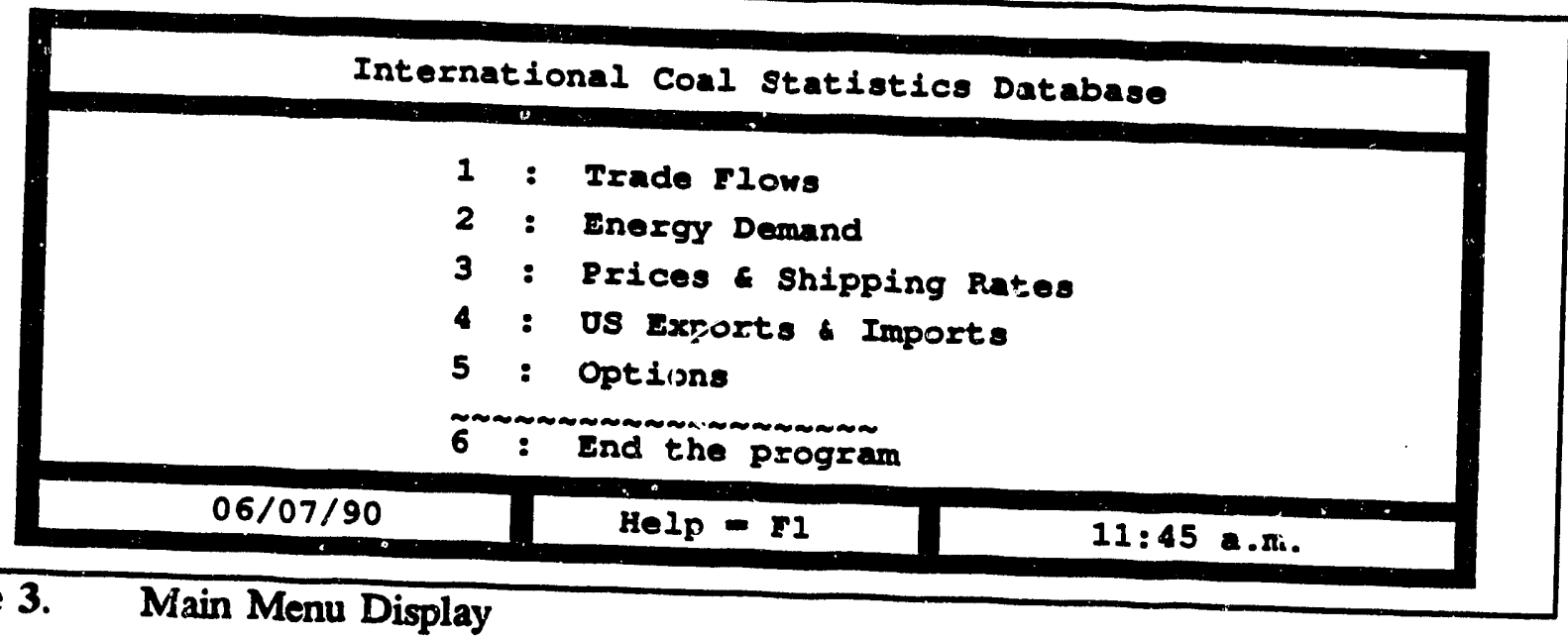

\section{4.f.i Operations and Data Retrieval}

\section{4.f.i.A Main Menu Selections}

The ICSD operates by using dBase programs to create a menu system, operating programs and data storage and makes automatic transitions into Lotus whenever spreadsheet capabilities
or graphics are needed.

The menu system is organized around the four types of data described in 1.2.b.iv. A user need only understand what the four types of data are and which may be needed to respond to a query in order to make the initial selection from the main menu. The initial menu selection will lead to a submenu of procedures for querying that type of data, followed by programs that interactively select and display responsive data. On-line help is available in the form of a pop-up screen that briefly explains each menu selection. All operations begin and end at
the main menu.

In addition to the four menu choices corresponding to major data types, there is a fifth choice from the main menu that controls access to various system maintenance programs. System maintenance options include routines to rebuild index files in case of a malfunction, an annotated file list explaining the purpose of existing files and allowing newly created files to be noted, and a program to either copy files or restore corrupted files to their original contents. There is also a further sub-menu of miscellaneous programs that perform various worksheets, printer set-up, and so forth.

The menu system is organized like an inverted tree (Figure 2), with the main menu at the top, five operating menus (the first major program branches) beneath that, and further menus and 
decision points beneath each of the five operating menus. All unajor decisions are made through the main menu, and it is necessary to retum to the main menu in order to switch to a different branch of the structure. Help on the meaning of menu choices may be accessed by hitting the F1 key. By convention, the border of the main menu is cyan, secondary menus have a red border, and tertiary menus are in blue.

\section{I) Trade Flows}

The Trade Flows selection contains both time series and matrix views of the intemational trade in coal between importing and exporting countries and regions. It should be used for official data on how much coal went from a nation or region to another nation or region. Data are complete for all years between 1980 and 1990. Data exist for steam and metallurgical coal, and the rombination of the two.

One of the limitations of either Lotus or dBase is the presentation of multi-dimensional data. It is not possible to get all possible information from this type of data in a simple twodimensional table. To compensate for this, and to make available the most significant views of the four-dimensional arrays of importer / exporter volumes by year and coal type, the ICSD offers separate choices for either a time series or an importer / exporter matrix or a combination of the two. Between the three possibilities, it is possible to see every possible view of the data. Market share penetration analysis for both importer and exporter is available from the matrix view. Trade flows are explained in more detail in Section 2.4.f.i.B.

\section{II) Energy Demand}

The Energy Demand selection contains historical data and projections that show how major industrial economies use coal, how much they depend on imports and how coal usage compares with other primary fuels. Historical data range from 1980 to 1989 , with projections for many variubles through 2010. Data may be accessed using either color or monochrome graphics. The dBase program generates multiple reports on coal use in the electric utility and industrial sectors, shows coal import balance, and projects coal imports through 2010. Data are most complete for OECD European countries and Japan. Not all data elements are available for smaller industrial economies.

\section{III) Prices \& Freight Rates}

The Prices \& Rates selection contains a commercial data series from Coal Week Intemational (CWI). Data are taken from the monthly issue nearest the end of a quarter for each quarter since 1980. Changes in the data series by CWI affect some data elements during some periods. Prices include both prices at origin and prices at destination for steam coal and prices at origin only for metallurgical coal. Data includes significant pricing variables such as heat content per unit of weight, ash content, volatility, etc. Freight rates are reported price quotes from main coal exporting ports of major coal exporting countries, varying by ship size and port of destination. 
For copyright protection reasons, these two datis bases are not supplied on non-EIA versions of the ICSD.

IV) U.S. Exports \& Imports

This selection contains Census Bureau figures derived from U.S. Deparment of Commerce data on coal shipments entering and leaving the United States. The period of coverage begins in January, 1980 and extends to December 1990. Coal shipments are reported in short tons with corresponding total dollar values. For export shipments, the free alongside ship (f.a.s.) value is given; for imports the cost, insurance and freight (C.I.F.) value is given. EIA ordinarily applies several filters to these data for publication purposes which have not been applied in the ICSD. Specifically, EIA suppresses records where average prices exceed $\$ 200.00$ per ton (usually where small quantities are shipped on an experimental basis to test the suitability of coal for a particular boiler) or where price changes fluctuate by 1,000 percent or more. These filters apply primarily to small shipments and do not affect weighted average prices significantly. Documentation for these alterations may be found in the notes accompanying EIA's Quarterly Coal Report. If desired, the Custom Query menu choice may be used to construct similar filters.

V) Options

The Options selection contains configuration, file maintenance and miscellaneous options. Configuration should be selected when the system is first used. There are also option selections that restore index files, list all files with an explanation of their purpose, and backup files. The Options selection also leads to a series of miscellaneous options. 


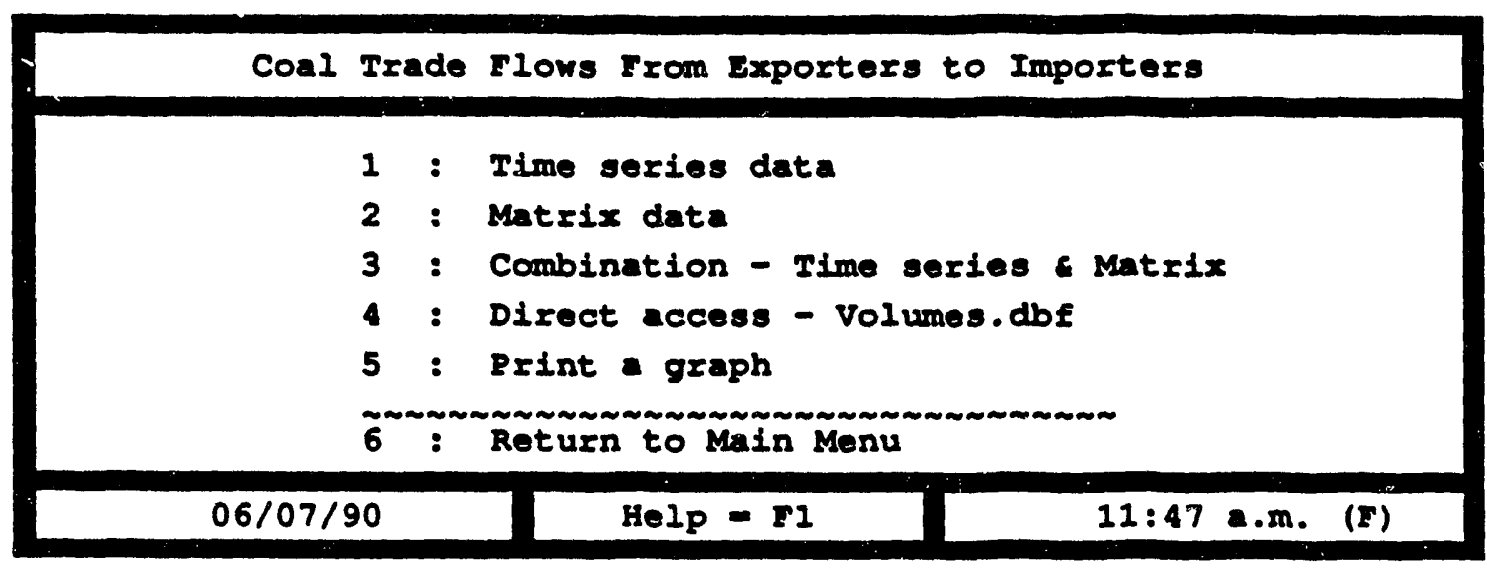

Figure 4. Trade Flows Menu Display

\section{4.f.i.B Coal Trade Flows Menu Selections}

\section{I) Trade Flows Option 1: Time Series Data}

After selecting Time Series, the importing country or countries must be specified in the indicated space. One country is specified at a time. If the program can't understand the name of the -Juntry requested, a list of possible countries will be displayed. Once the first importing country has been entered, the program will ask whether the user wishes to see that importer's trade with a particular country or with all countries. Depending on the response to this latter question, the process of entering importing countries continues until either the user enters $Q$ to quit or the maximum of six has been reached. Note that the initial choice of a particular exporter will apply to coal importers selected subsequently. That is, once the user has requested Japan's imports from Australia, designating additional importing countries would also show their imports from Australia.

When the query is completed, a worksheet is loaded and the data found in response to the query are loaded into the worksheet automatically. Program control then switches to Lotusstyle menus. The initial chcice is Report, Print, Graph, Free, and Exit. The menu choice, Report, shows the raw data found in response to the query, i.e. how much coal was exported by the chosen exporter to the chosen importers between 1980 and 1986 by coal type. As is the case throughout the ICSD, type 1 refers to steam coal, 2 to metallurgical, 3 to both.

The menu choice, Print, simply prints out this data, while the choice, Graph, leads to a submenu on what data should be graphed, followed by a further submenu on how they should be graphed - line plot, stacked-bar, or regular bar graph. When specifying the type of data to be graphed (all three coal types for a single country as opposed to all six countries for a single coal type) the cell pointer will be positioned at the top of a list of countries. Keep the 
pointer in the same column, then move to the row containing the desired country name and hit enter. After specifying the type of information to be graphed, there are other choices which cover whether the graph should display monochrome or color (if the system is capable of displaying color) and whether it should be saved for future printing using the Lotus Print Screen program. After making selections for the type and display attributes, select View to see the graph.

The final main menu choice, Free, allows unhampered access to the entire worksheet starting in the upper left comer, in case the user wishes to examine portions of the data, save the information in a different file, or whatever. To retum to the ICSD menu structure, enter $A L T+M$ simultaneously, and then exit nomally.

To exit from the menu choices, hit enter twice.

\section{II) Trade Flows Option 2: Matrix Data}

A matrix of importers arrayed with exporters must first be specified. This is done by selecting a year and coal type; only one year can be selected at a time. Once complete, data are retrieved from the Volumesl.dbf and converted to a worksheet

- for use with Lotus.

Lctus will be loaded and the submenu will appear. The principal choices are the same as in Time Series: Reports, Print, Graph, Free and Exit. In addition, there is a choice, Units, which allows the user to specify if data should be displayed in short tons or metric tons.

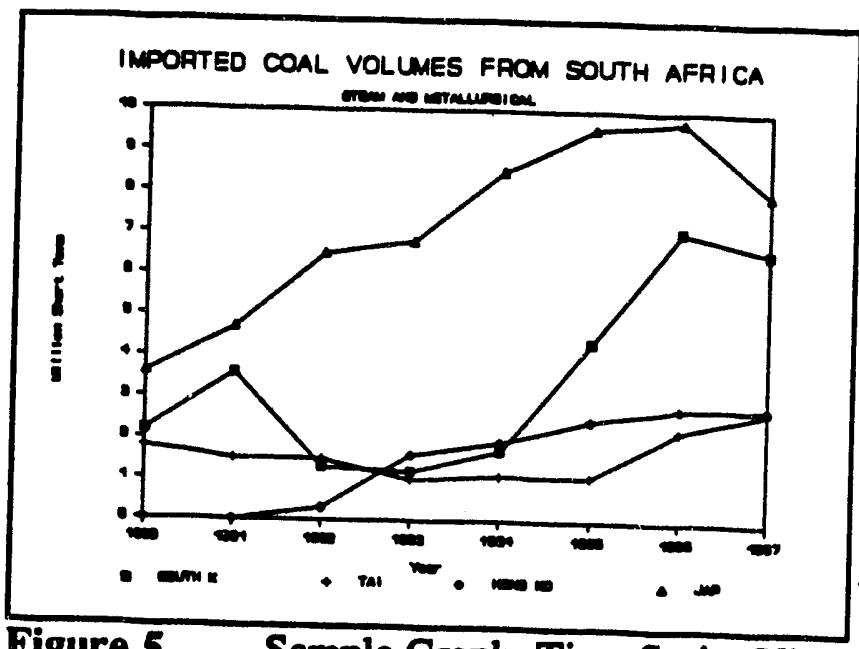

Figure 5. Sample Graph: Time Series View

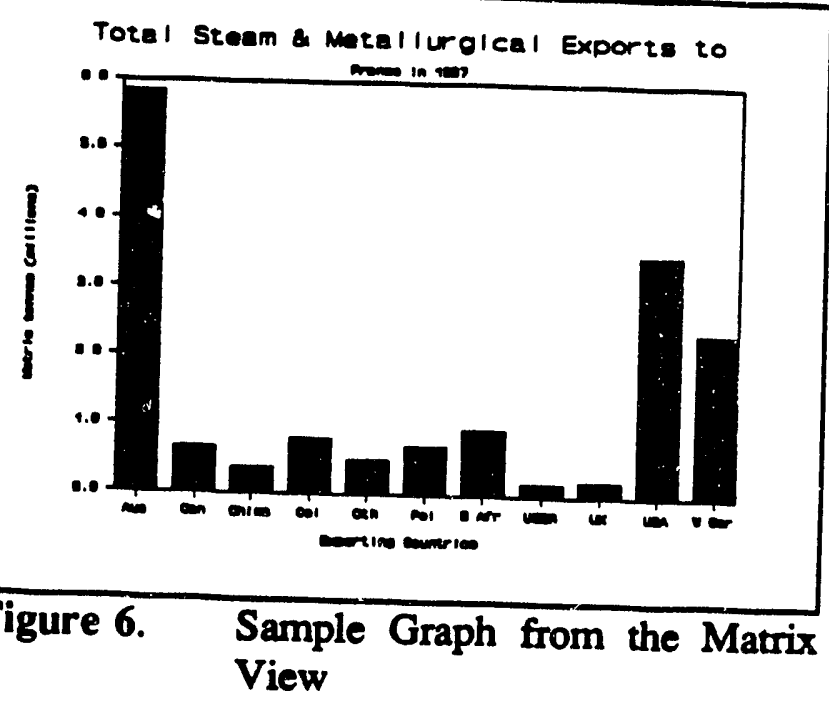

There are three main Reports: Trade Volumes, Exporter Market Shares and Importer Market Shares. The first displays volumes in the Units selected, while the latter two are in percent. Exporter Market Shares shows the percent of an exporter's total coal exports (for the selected coal type in the selected year) that were accounted for by a given importer. Conversely, Importer Market Shares shows the percent of an importer's total coal imports for the year and 
coal type in question that come from a given exporter. As with all reports displayed on the screen from Lotus, the enter key should be hit several times to retum to the menu system.

The Print selection prints either of the three reports. The Free and Exit selections work as specified for the Time Series selection.

Graph is somewhat different. This time the cell pointer marks a number beside the name of a country or region. It is kept in the starting column and moved down until the importing country or region of interest is reached. The enter key is then hit and a graph is displayed of the chosen country or region's imports from each coal exporter during the year in question. Whichever data type is chosen, it is possible to see the graph as a line plot, a stacked bar graph or a regular bar graph. It is also possible to select whether it should be displayed in color or monochrome.

\section{III) Trade Flow Option 3: Combination - Time Series \& Matrix Data}

The use of a combination is a compromise resulting from the inability to display all facets of coal flows data at once. Instead of both steam and metallurgical, the Combination selection only shows data for a single coal type, which must be selected first. Although only one coal type must be chosen, the data is constructed yearly across the 1980 to 1986 time period and over all countries pertinent to a given coal flow choice. After entering the coal type, the program then selects data from the Volumes1.dbf and loads Lotns for further work with the data. Once in Lotus, the

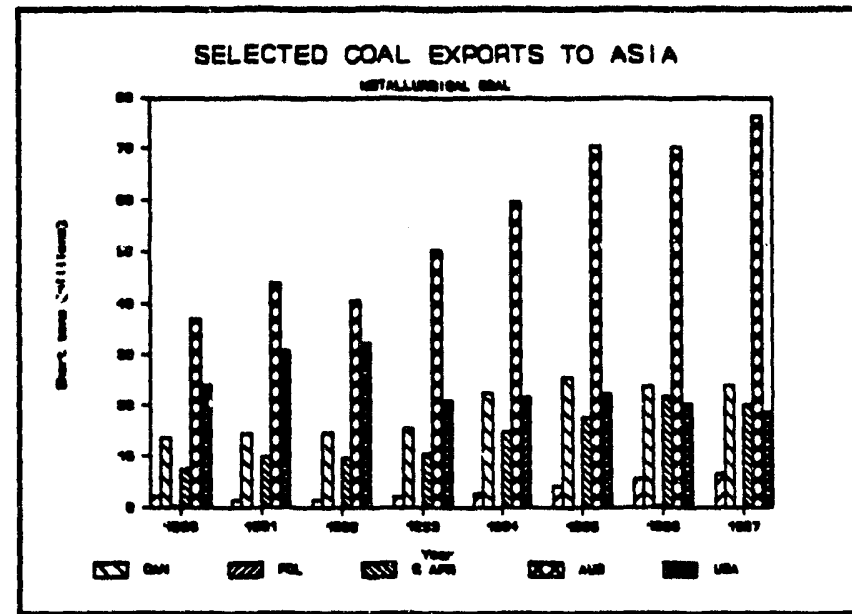

Figure 7. Sample Graph: Combined View initial menu is similar to the other Lotus menus, except a choice for Country has been added. Using the cellpointer technique of moving to the name of the country of interest, a single country or region is selected. However, it is still possible to review data for all countries by selecting "All" from the Reports menu. A second choice on the Reports menu permits only data for the selected country to be reviewed. In either case, the print menu allows comparable reports to be printed. The Graph menu shows time series import data, but shows only imports from the major coal exporters (rather than all exporters as is the case in the Matrix menu selection). Here,too, graph output may be viewed in one of several graph types in either color or monochrome. Similarly, graphs may be saved or not saved for future printing.

IV) Trade Flow Option 4: Direct Access - Volumes.dbf 
Selecting this option causes the ICSD system to stop and the dBase command interpreter to take over. Therefore, users should be familiar with dBase commands and the necessity of closing files after using them before opting to use it. If it is selected the Volumes.dbf will be in use with the Volumes.ndx open. This data base holds trade flows data in a structure where field headings, prompt. Damage commands to use Volumesl.dbf and index should be given from the dot to the ICSD. Use F10 as a means of result if all open files are not closed before returning

\section{V) Trade Flow Option 3: Print a Graph}

This choice loads the Lotus 1-2-3 print graph program so that any graphs that may have been saved when using menu selections 1 - 3 may be printed. Full instructions for using the program are contained in the Lotus manual. However, once the "hardware" setting for the directory holding graphs has been changed to the ICSD directory, operation should be selfexplanatory. Graphs are selected for printing, using the space bar and enter key, and the Go
command given. 


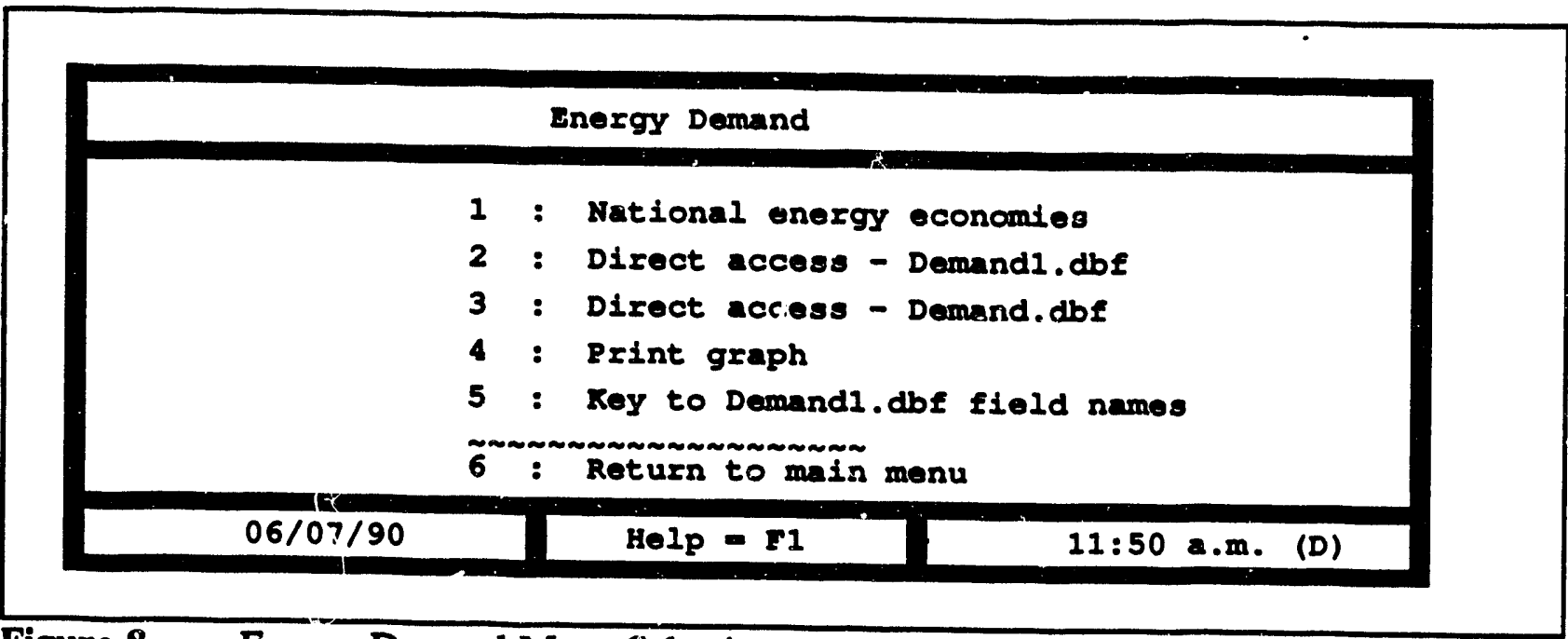

Figure 8. Energy Demand Menu Selections

\section{4.f.i.C Energy Demand Menu Selections \\ I) Energy Demand Option 1: National Energy Economies}

This selection presents information on how the major industrial economies use coal. It begins with the designation of a country to be analyzed. The name of the country is entered where indicated or a question mark may be used to call a listing of possible countries. Records for the seiected country are then accessed and transferred to Lotus worksheet format for reading into the demand worksheet.

The usual worksheet menu comes up after data have been loaded. The choices are Report, Print, Graph, Free or Exit. Each of the first three selections leads to a submenu of different reports that may be displayed on the screen, printed, or viewed as graphs:

1. Primary - Shows primary energy consumption by major fuel type for the years 1980 - 1988, with projections through the year 2010.

The screen can only hold a limited number of years. Therefore, it is

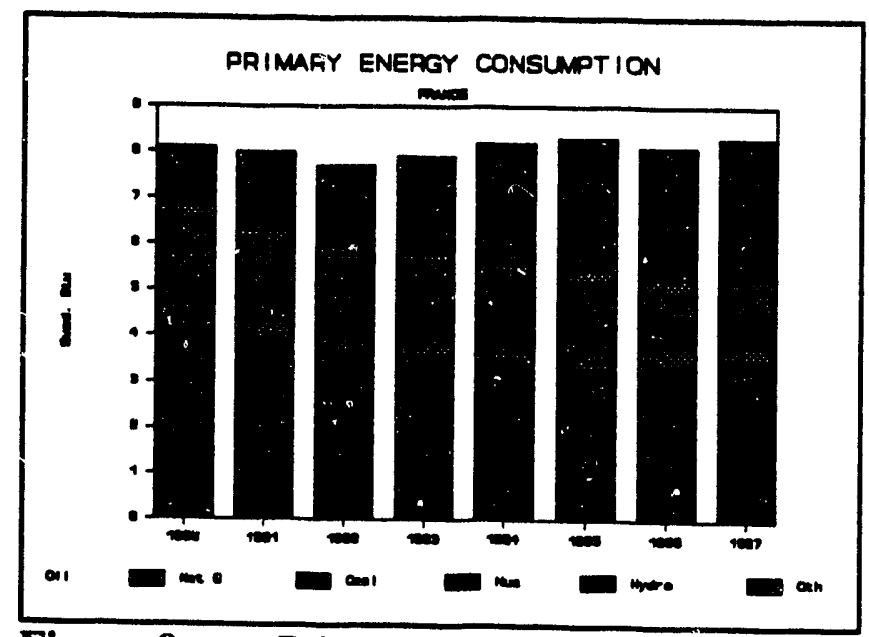

Figure 9. Primary Energy Demand necessary to move the cursor to the right to access later years. Units are Btu's. In report mode, return to the main menu by hitting enter several times. 
2. Utility - Shows energy consumption by electric utilities for the same historical and forecast periods. Units are Btu's. Fuel types include oil, gas, coal, nuclear, hydro and other.

3. Industry - Shows primary energy consumption in the selected country's industrial sector. Units are Btu's. Sarne fuel types as for utility report.

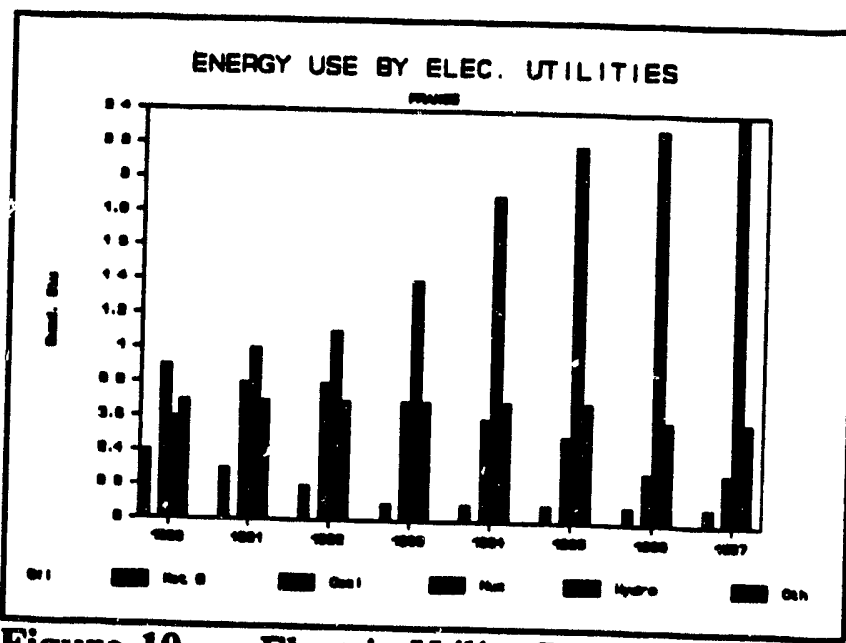

Figure 10. Electric Utility Demand

4. End Users - Shows total coal consumption by fuel use sector. Units are millions of metric tons. The sectoral breakdown between end users covers electric utilities, industry, and residential and commercial, further broken down by coal type for each end user category. Historical coverage begins in 1982.

5. Coal Balance - Breaks down coal consumption, production and imports to show the total coal balance of an individual economy, projected through 2010. Coal types are provided for each category (i.e. consumption, production, and imports) including steam (hard coal and lignite) and metallurgical.

6. GDP - Shows projected gross domestic product and population for $1990-2010$. This information is not graphed.

7. Others - Leads to a further menu with choices for:

- Forecasts: Projects imported coal demand under basecase, low demand and high demand scenarios. Units are millions of short tons. Projections are made for steam and metallurgical coal.

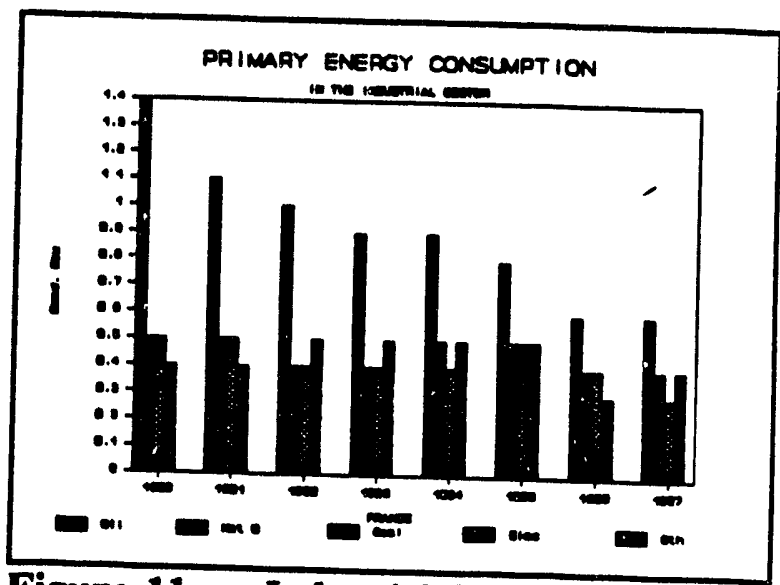

Figure 11. Industrial Sector Demand For graphs, a composite representing the sum of the two coal types is used.

- Electricity production: By fuel type, with capacity in Gigawatts and production
in Terawatts. 
Steel Production: By process, with data on imports and exports, apparent consumption, and pulverized coal injection sapacity.

II) Energy Demand Option 2: Direct Access - Demand1.Dbf and Demand.Dbf

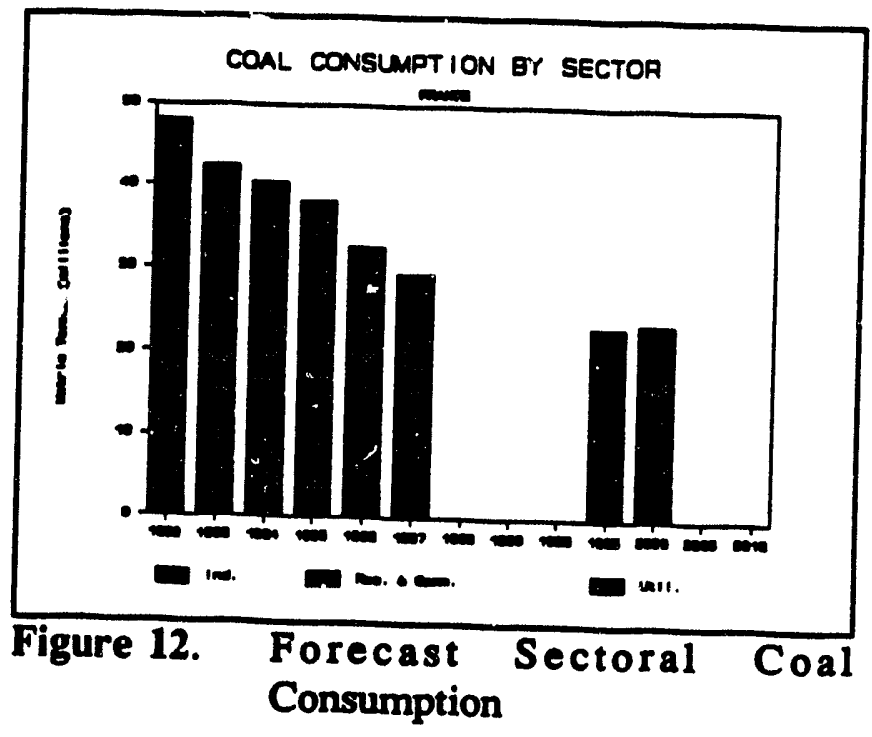

The purpose of direct access is to permit analysis of the wealth of data stored in these data bases by use of dBase III. The data in both data bases is exactly the same, but the structure of the two data bases is completely different. The structure of Demand1 uses as field headings the key variables about individual energy economies while Demand uses years as field headers. Since the abbreviations for key usage variables in Demandl are certainly not self-explanatory, a listing of what each refers to is provided in an on-line help selection (Choice 5) and reproduced in the program listing of D5.PRG in the Program Maintenance Manual.

There are many important analyses made possible through direct access. For instance, to rank countries by the size of their potential coal imports in 1990, use the demand1.dbf, index on 1000-RMP_TOT to a chosen filename, and LIST FIELDS COUNTRY, IMP_TOT TO PRINT FOR YEAR=[1990]. Subtracting the import total from a larger number to create the index assures that the results will be listed in descending order.

III) Energy Demand Option 3: Print Graph Loads the Lotus Print Graph program for any graphs created with the first menu
selection.

IV) Energy Demand Option 4: Key ro Demand1.Dbf Field Names

This selection serves as an on-line reference to the dozens of field names in the Demand1.dbf. Its only purpose is to avoid having to consult the manual while working.

The explanation of field names is needed to use the direct access to the Demand1.Dbf. 


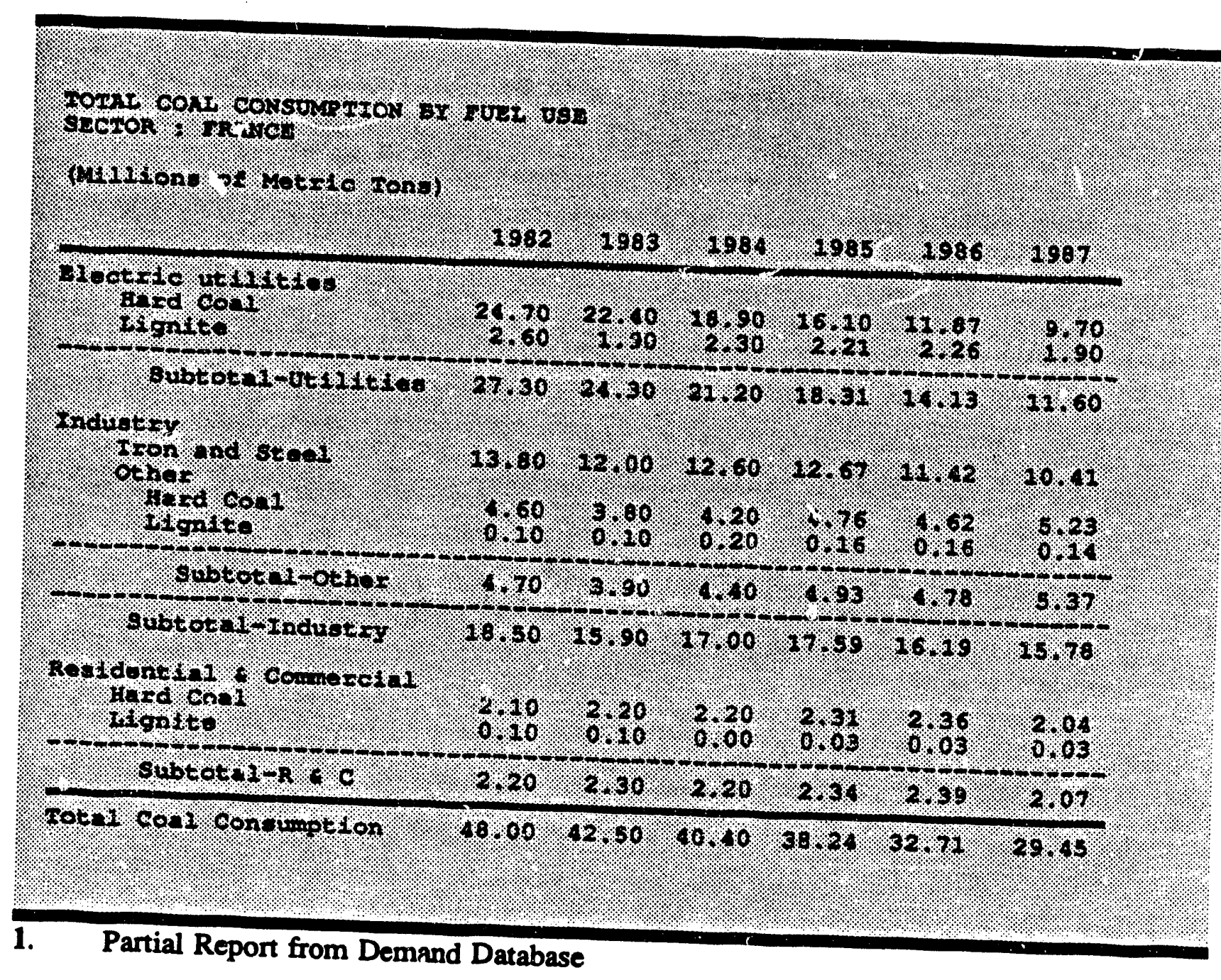

\section{4.f.i.D Prices and Freight Rates Menu Selections}

Unlike either the flows or demand menu choices, the prices and freight rates menu, as well as being reported is not a total already preparn, query transaction data bases. The information individual transactions must be selected by elsewhere. Therefore, some combination of data display. A choice must also be made che user in order to construct the format of the be reported. So the first menu choice must be exectected subset of transactions should third choices. The first selects a type of output executed in sequence with either the second or the first menu choice is used again). After selectich, once selected, will not change (unless either prices.dbf or freight.dbf by selecting eithering a report output type, a query is made of choice 1 then either 2 or 3 .

I) Prices \& Freight Rates Option 1: Report Format 


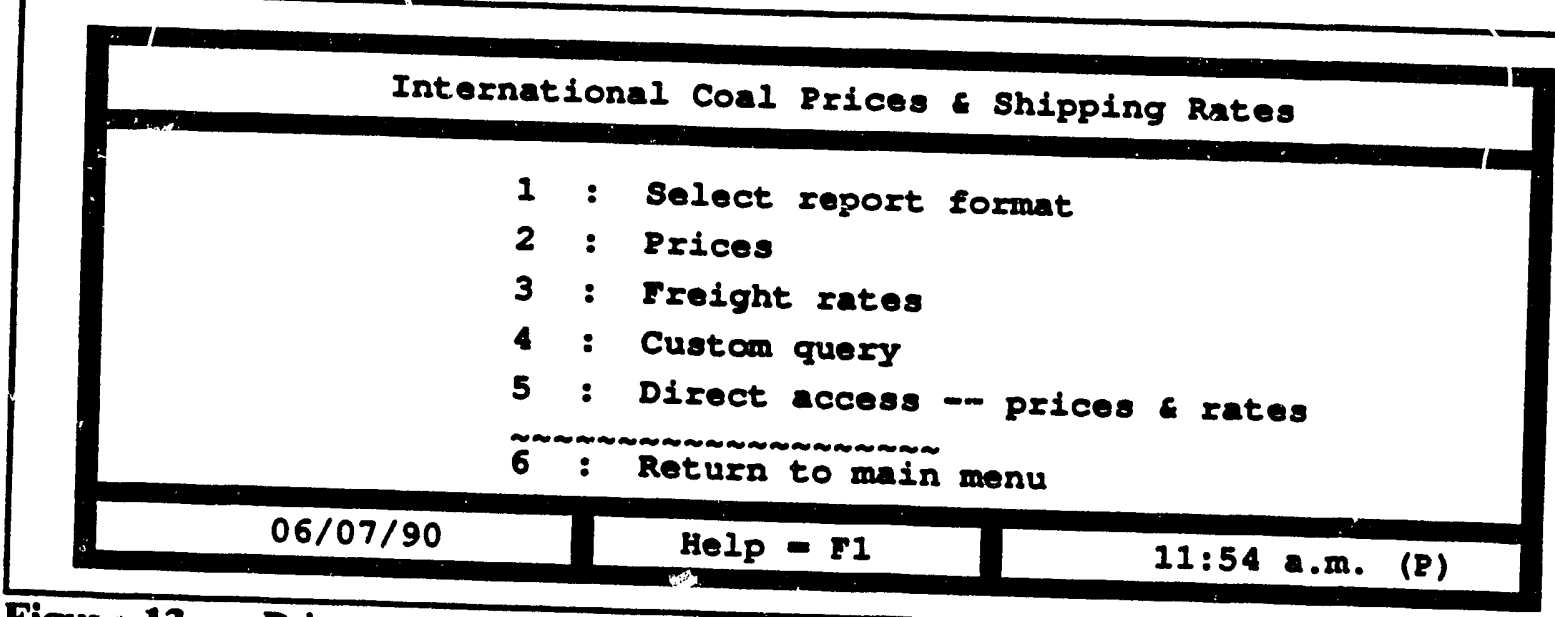

Figur: 13. Prices and Freight Rates Menu Display

The ICSD offers six different types of report outpur:

1. Screen Once sent to the screen, output may be stopped temporarily by hitting C.RL + Nun Lock or permanently by hitting ESC. The program uses the dBase Display command to send a screen of information at a time, with a pause to allow the user to review the data before proceeding.

2. Printer The report format is slightly different from Screen since more lines per page and more variables may be reported. The program will check if the printer is on and display 2 waming message in case it needs to be turned on. Unlike the screen, the data base to be output.

3. Text The text file is stored under the name P2.Txt for a query to the prices data base or under P3.Txt for a query to the Freight.dbf.

4. Data base An intermediate data base, either P2.Dbf or P3.Dbf, is created to hold the results of the query. It may be accessed using the command interpreter for further
analysis or the preparation of user-created reports, sorts, queries, etc.

5. Worksheet Data are transferred to ornrksheet format, Lotus is loaded, and the transferred worksheet is brought in. The worksheet is less sophisticated than others in the system, the idea being that the user will manipulate the data and design the worksheet as required. The only buiit-in facility is the Lotus Data/Query/Extract command which results in a graph of the selected prices. Many user-designed queries
are possible.

6. Average The key variables of the chosen records are averaged. Note that only records having a non-zero value in the variables being averaged are included. For 
instance, if term prices are averaged, only records where either the upper or lower term price bound is greater than zero will be included. Since the dBase average function does not specify on its own how many records were averaged to produce the total, "talk" is left on so this information will appear in the upper left-hand comer of the screen.

\section{II) Prices \& Freight Rates Option 2: Prices}

Information in the prices.dbf is derived from the McGraw-Hill publication, Coal Week International. The reported prices are taken from industry sources and are subject to the limitations explained in the notes to the World Scan section of CWI. Prices are available for coal at the port of origin or the port of destination for steam coal, and for prices at the port of origin for metallurgical coal. Since CWI has not adhered to a consistent format, there are some variations in presentation of data. For instance, in the early 1980 's a range of spot and term prices was given, except not for all ports. More recently, the range has been omitted, but there is greater coverage by certain variables, such as vessel size. The ICSD includes as much data as possible in a broad format. Since direct access is possible, the broad nature of the ICSD coverage may be limited by narrowly drawn queries.

The procedure for accessing the data is:

1. Select a report format

2. Specify whether prices at origin or destination are desired (for steam coal), or just prices at origin (for metallurgical coal). The data base is then searched for the requested records, which are then reported in the previously selected manner.

\section{- III) Prices \& Freight Rates Option 3: Freight Rates}

The selection of a query to the freight rate data base is similar to a price query. If an average is selected, the key variable is ship size, with the division made between colliers of less than or equal to 55,000 tons or greater than that size. Averages are prepared for the period selected in the query.

\section{IV) Prices \& Freight Rates Option 4: Custom Query}

Since there are so many possible variables that may be of interest to the user in either the prices or freight rates data bases, the dBase filter program is used to allow custom made queries to be built. The first step is to complete the components of the filter by specifying variables of interest, logic or value operators and their sources or connections. An initial field 
name has been entered, since dBase does not permit the filter to be even partially prepared in advance unless some aspect of the filter is in place. The pre-selected item simply corresponds to the earliest date in the data base. The following screen depicts the operating environment for establishing a dBase filter. Additional instructions may be found in the dBase manual under the CREATE / MODIFY QUERY command.

\section{V) Prices \& Freight Rates Option 5: Direct Access}

The purpose of direct access is to permit analysis of the wealth of data stored in these data bases by use of dBase III. Option 5 permits the user to access both prices and freight rates directly from the complete data base rather than from a subset which results via the price or freight choices separately. 


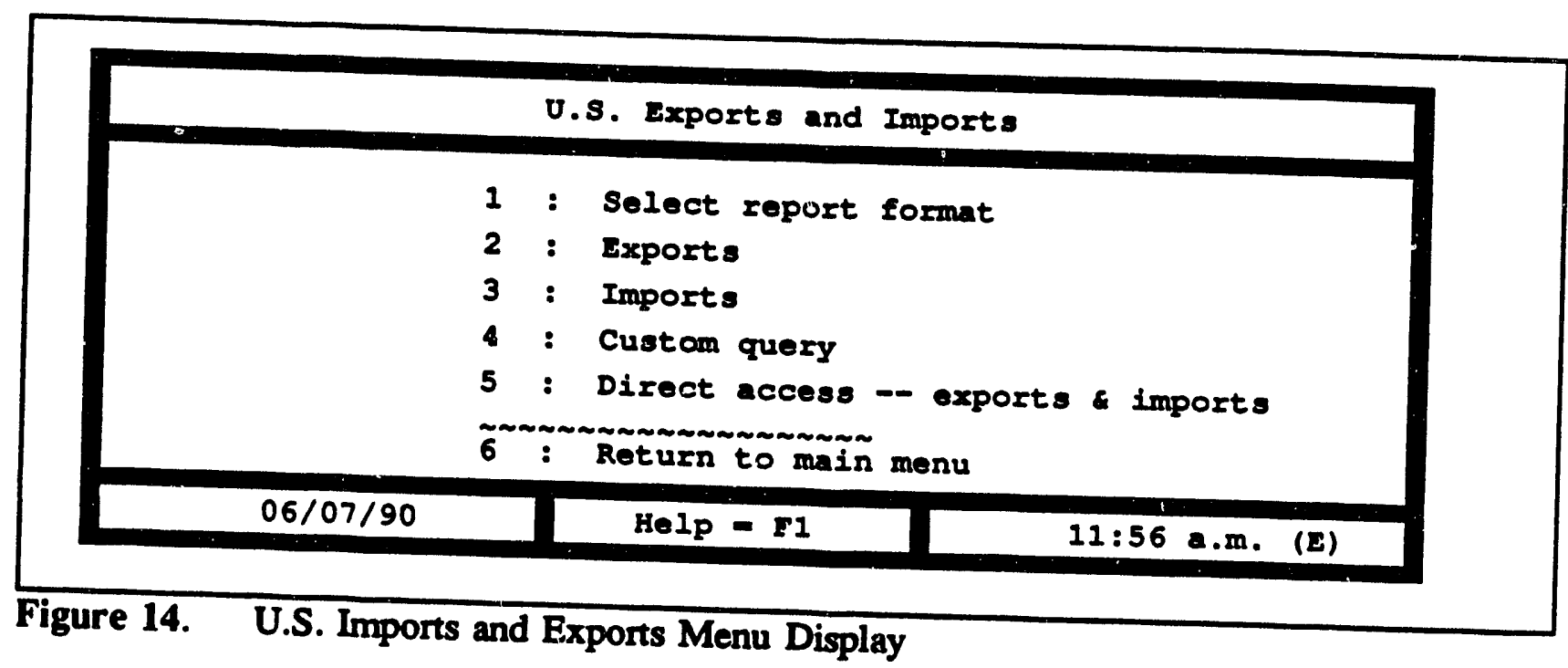

\section{4.f.i.E The U.S. Exports and Imports Menu Selections}

Unlike either the flows or demand menu choices, the U.S. imports and exports menu queries transaction data bases. The information being reported is not already totally prepared user. A choice must also be made on how the selected subsetions must be selected by the reported. So the first menu choice must be chosen in sequence transactions should be choices. The first choice selects a type of output which, once with the second and third (unless the user chooses the first menu choice aut which, once selected, will not change query is made of either the U.S. exports aice again). After selecting a report output type, a choice 2 or choice 3 .

\section{I) Export \& Import Option 1: Select Report}

This functions quite like the report selector for the prices menu. However, here is an additional choice of summary report, to sum key variables identified in response to the query
specified for either the export.dbf or import.dbf.

II) Export \& Import Option 2: Exports

Queries to the export data base depend on specifying a range of dates, a country or region receiving the shipment from the U.S. and the U.S. port or region that originated it. It is possible to specify an individual country and a region of U.S. ports, or a region of the world receiving shipments from a single U.S. port. If the query does not depend on a particular selection should be made, port or receiving country will do) the individual country or port selection should be made, rather than the regional selection, since the individual selections list 
a choice that represents all countries or ports. For instance, to select records without regard to the country where the coal was sent, enter 999 in the place indicated for a response.

The search procedure is optimized for finding records for a single coal type for either a single country receiving exports or a region of the world receiving U.S. coal exports. Queries of this type will produce a fairly quick response despite the size of the data base. However, queries that ask for both steam and metallurgical coal exported to all countries can not take full advantage of the optimizing procedure and are almost as slow as a full dBase search through all records. 


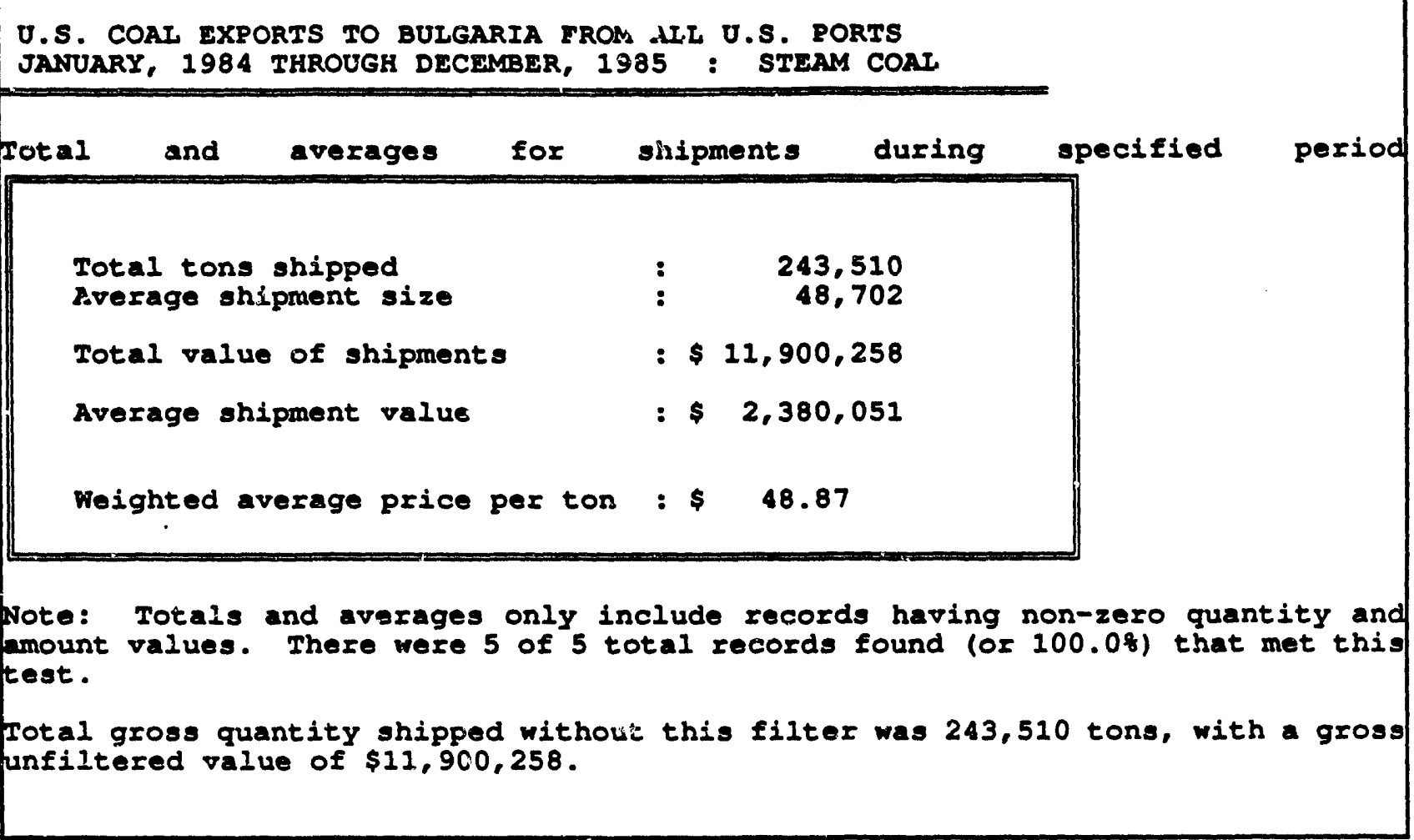

Figure 15. Sample US Coal Exports Report

III) Exports \& Imports Option 3: Imports

The procedure for querying the imports data base is similar to that for exports. The oniy major difference is that there are fewer import records, so that queries are reported more rapidly, and there are no variables for port or region where the shipment arrived in the U.S.

\section{IV) Export \& Import Option 4: Custom Query}

Since there are so many possible variables that may be of interest to the user in either the export or import data bases, the dBase filter program is used to allow custom made queries to be built. The first step is to complete the components of the filter by specifying variables of interest, logic or value operators and their sources or connections. An initial field name has been entered, since $\mathrm{dB}$ ase does not permit the filter to be even partially prepared in advance unless some aspect of the filter is in place. The pre-selected item simply corresponds to the earliest date in the data base. The figure 14. screen from the previous Prices \& Freight Rates section depicts the operating environment for establishing a dBase filter. Additional 
instructions may be found in the dBase manual under the CREATE / MODIFY QUERY command.

V) Export \& Import Option 5: Direct Access

The purpose of direct access is to permit analysis of the wealth of data stored in these data bases by use of dBase III. Option 5 permits the user to access both exports and imports directly from the complete data base rather than a subset which results via the export or import choices separately. 


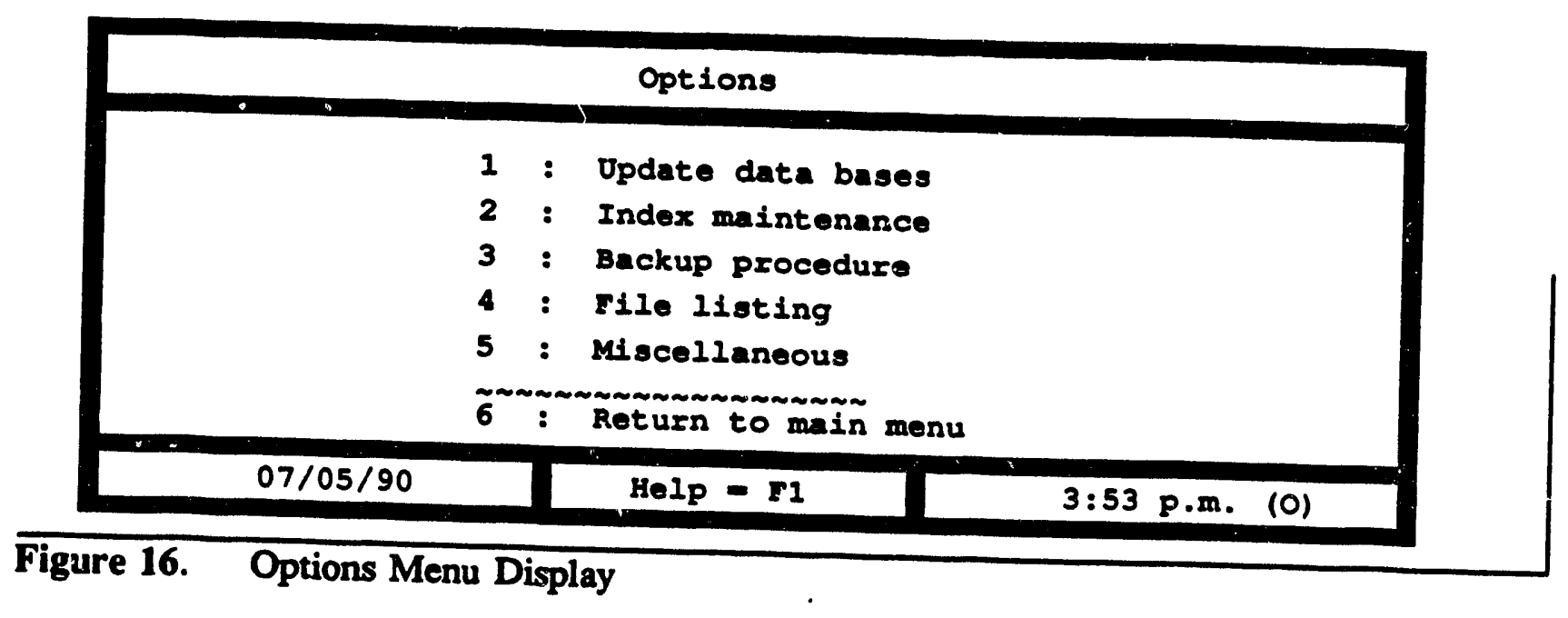

\section{4.f.i.F Options Menu Selections}

The ICSD offers several additional data tase management or maintenance programs that may be of assistance to the user. These programs are organized as shown above, with two submenus offered after selection of the first or fifth choice. The first submenu, for update data bases. The second is a collection of miscellaneous programs and utilitiestained in the useful, and includes routines to initialize printers, use the dBase and utilities that may prove 1-2-3 worksheets, and the like.

\section{I) Options Menu Option 1: Update Data bases}

Because of their importance, data update procedures are reviewed in a separate section (2.5.c).

II) Options Menu Option 2: Index Maintenance

The queries executed by the ICSD depend on the existence of uncorrupted index (key) files that organize data in the specific way required by the programs. Index files can become compted in several ways, but the most likely is for data to have been entered in the data base without the related index file or files being open. Corruption of index files can be avoided when custom routines are being executed by always opening the necessary files, but the user will have to carefully review the annotated file list (described below) and naming fonventions to find out which indexes go with which data bases. If the integrity of the index unable to successfully recover, it may be restored by running this option. Because dBase is stopped or a loss of data may result. It takes abou to the reindexing process, it must not be 


\section{III) Options Menu Option 3: Backup Procedure}

In order to maintain the integrity of data in the ICSD component data bases, it is possible to use this option to replace any data base that may have been corrupted with a special copy of the original data base that is maintained in a separate directory.

The advantage of the backup capability is that it is possible to ensure that all data is correct as originally supplied. The disadvantage is that a further 8 megabytes of disk storage is
needed for the backup files.

The backup option depends on the ICSD having been installed with both the system files and the backup files. Refer to the installation procedure.

\section{IV) Options Menu Option 4: File Listing}

The File Listing option provides a quick, on-line way of determining what each ICSD file does. As there are more than 150 files, this racility can be essential for keeping track of files. In addition, the user may create other files either from dBase or Lotus. The File List option will detect the existence of a new file, and allow the user to annotate for future reference. A final feature of the option is the capability of printing out the listing.

V) Options Menu Option 5: Miscellaneous

Included in this section are programs that may be useful but are of secondary purpose. These
include:

- Dropping to the dBase command prompt level, for experienced dBase users wishing to do further work on the ICSD data bases. Loading a new Lotus 1-2-3 worksheet while still remaining in the ICSD
directory.

- Loading a DOS shell to run other programs while still in the ICSD environment.

- Sending set up strings to the user's printer. 


\section{4.f.ii Date Sources}

\section{4.f.ii.A Periods Covered in Data bases}

The information contained in the ICSD data bases is current up to the following dates:

World coal trade (Volurnes.dbf and Volumesl.dbf):

December 1989

Coal demand of national economies (Demand.dbf and Demand1.dbf):

December 1989

U.S. imports and exports of coal (Imports.dbf and Exports.dbf):

December 1990

Spot market prices at major ports and freight rates (Prices.dbf and Freight.dbf):

June 1990

Further information on data currency is contained in the discussion of separate data bases below.

\section{4.f.ii.B World Coal Trade}

Information on the volumes of coal traded between courztries (also sometimes referred to as flows data herein) is taken from the Energy Information publication, Annual Prospects for World Coal Trade (Prospects). The data in the data base for any given year and coal type is exactly the same as that shown in the counterpart tables (A1 through A6) in the publication.

The following information on sources is a full listing of the sources cited in Prospects. This appendix provides supplemental historical data on worldwide steam, metaliurgical, and total coal flows from the coal-exporting countries to the coal-importing countries and regions for the years 1987 and 1988. Tables for 1980-1986 can be found in previous issues of Prospects, as follows: 1980-1984, Prospects 1987; 1985, Prospects 1988; 1986, Prospects 1989.

International coal trade statistics can be obtained from either (a) export statistics of coalexporting countries or (b) import statistics of coal-importing countries. Between any two countries for which both sets of data are available, the two sets may not be the same. 
Consequently, the worldwide coal trade figures obtained from summing up exporting country totals are not the same as those obtained by summing the importing country totals.

In Tables A1 through A6 of Prospects and the flows section of ICSD, import statistics were used, whenever available, as the basis of the historical trade data in the body of the tables above the Balancing Line. For OECD countries, which accounted for 60 percent of world coal exports and 65 percent of world coal imports in 1988 (Table A6), data on coal imports by coal type are published in the OECD/International Energy Agency report, IEA Coal Information 1989. That report provides a uniform set of data on coal imports by the OECD countries by coal type, i.e., steam and metallurgical, and is the principal source of the data in Tables A1 through A6. For non-OECD countries, a number of sources were used. In some cases, data on coal imports by coal type are available from the overall trade statistics of the importing country. In other cases, only total coal import data are provided in the country trade statistics, and the breakdown for steam and metallurgical coal was estimated by EIA. In still other cases, no importing country data are available, and the imports were estimated by summing up the data of exporters for that country. Data sources or the derivation of the data for individual countries are shown below.

The Balancing Item contained in the tables generally is the difference between the total of individual country coal exports and reported imports summed. Shipments in transit and distribution losses are the principal reasons for the discrepancies between export and import statistics for coal flows as a whole. Another issue is the sometimes different definitions of steam coal and metallurgical coal by exporters and importers. Although total coal trade reported between any two countries may agree, the more detailed data on steam coal and metallurgical coal may not agree, because the coal may have been used in the importing country in different ways than initially anticipated when it was shipped from the exporting country.

Sources: Export Statistics

1988:

OECD Countries (except the United States): International Energy Agency (IEA), Coal Information 1989 (IEA Coal Information 1989) (Paris, 1989).

United States: Monthly Report EM-522.

Non-OECD Countries (except Colombia, U.S.S.R. and "Other Exporters"): Intemational Coal Report's Coal Year 1989 (ICRCY 89)(London 1989) and Coal Year 1989 Supplement.

Colombia: Estimate from Office of Coal, Nuclear, Electric and Altemate Fuels (CNEAF) Includes El Cerrejon mines and others. 
U.S.S.R.: Vneshnaya Torgovlya 1989, p. 61.

Other Exporters: Estimated from importing countries' statistics (see below). These countries include: France, Indonesia, Venezuela, India, Vietnam, Czechoslovakia, and others.

\section{Sources: Import Statistics}

1988:

OECD Countries (except the United States and Ireland): IEA Coal Information 1989.

Europe and Mediterranean:

Algeria: Exporters' data, United States (EM-522), Australia (ICRCY89, p. 25), Poland (ICRCY 89, p. 30).

Egypt: Exporters' data, United States (EM-522), Australia (ICRCY 89, p. 25), Canada (ICRCY 89 p. 27), Soviet Union (Vneshnaya Torgovlya 1989, p. 61).

Ireland: Imports are as reported in IEA Coal Information 1989 except Colombia which was reassigned from "other."

Israel: ICRCY 89 Supplement, p. 5.

Morocco: Exporters' data, United States (EM-522), United Kingdom (ICRCY 89, p. 31), Colombia (ICRCY 89, p. 28).

Yugoslavia: IEA Coal Information 1989. Type assigned according to exporters' data, United States (EM-522).

Other: Exporters' data, Australia (ICRCY 89, p. 25), Canada (ICRCY 89, p. 27), Poland (ICRCY 89, p. 30), Colombia (CNEAF Estimate), and United States (EM-522).

Non-OECD Asia:

Hong Kong: ICRCY 89, p. 36.

South Korea: ICRCY 89 Supplement, p. 7. Imports of coal from "other" were assignea to South Africa and China according to market information, (Coal Week International, April 6, 1988, p. 2).

Malaysia: Exporters' data, Australia (ICRCY 89, p. 25) and Indonesia (Foreign Trade Statistics Indonesia Exports 1989). 
Taiwan: ICRCY 89, p. 40. Steam coal/metallurgical coal breakout was based on exporters'data for Australia, the United States, and Canada. Exports from South Africa and other countries were assigned to steam coal.

Other Asia: Exporters' data, United States (EM-522), Australia (ICRCY 89, p. 25), U.S.S.R. (Vneshnaya Torgovlya, p. 61), Indonesia (Foreign Trade Statistics Indonesia Exports 1989), China (Coal Advisory \#1, "China's Near-Term Coal Expectations"), East-West Center (Honolulu, Hawaii), May 19, 1988.

Eastem Europe:

Exporters' data, United States (EM-522), Australia (ICRCY 89, p. 25), Poland (ICRCY 89, p. 30), West Germany (ICRCY 89, p. 33), U.S.S.R. (Vneshriaya Torgovlya 1989, p. 61), China (IEA Coal Information 1989, p. I.43-44), Czechoslovakia (United Nations, Economic And Social Council, Economic Commission For Europe, The Coal Situation in the ECE Region in 1988 and Global Prospects for Coal, August 23, 1989). The steam coal /metallurgical coal breakouts for imports from the U.S.S.R. and Czechoslovakia were assigned.

South America:

Argentina: Exporters' data, United States (EM-522), Australia (ICRCY 89, p. 25), Poland (ICRCY 89, p. 30), Canada (ICRCY 89, p. 27), Colombia (Coal Statistics International, June 1989, p. 65).

Brazil: Exporters' data, United States (EM-522), Australia ICRCY 89, p. 25), Canada (ICRCY 89, p. 27), Poland (ICRCY 89, p. 30), Colombia (Coal Week International, March 7 , 1989, p. 4).

Chile: Exporters' data, United States (EM-522), Australia (ICRCY 89, p. 25), Canada (ICRCY 89, p. 27).

Mexico: Exporters' data, United States (EM-522), Canada (ICRCY 89, p. 27).

Other: Exporters' data, United States (EM-522), Colombia (CNEAF estimate).

Sources: Export Statistics

1987:

OECD Countries (except the United States): IEA Coal Information 1989.

United States: Monthly Report, EM-522. 
Non-OECD Countries (except the U.S.S.R. and "Other Exporters"): ICRCY 89 and ICRCY
89 Supplement, and ICKCY 88 .

Colombia: Exporters' data (Coal Division estimate).

U.S.S.R.: Vneshnaya Torgovlya 1989, p. 61. Steam coal/metallurgical coal breakout based on importing countries data, principally the Westem Europe OECD.

Other Exporters: Estimated from importing countries' statistics. (See below.) These ex,orters include: France, Indonesia, Venezuela, Indie, Vietnam and others.

\section{Sources: Import Statistics}

1987:

OECD Countries (except the United States): IEA Coal Information 1989.

Europe and Mediterranean:

Algeria: Exporters' data, United States (EM-522), Australia (ICRCY 88, p. 33), and Poland
(ICRCY 89, p. 30). Egypt: Exporters' data, United States (EM-522), Australia (ICRCY 88, p. 33), and U.S.S.R.
(Vneshnaya Torgovlya, p. 61).

Israel: ICRCY 89 Supplement, p. 5.

Morocco: Exporters' data, United States (EM-522), Australia (ICRCY 88, p. 33), Colombia (International Coal Report, February 23, 1989, p. 15). Yugoslavia: IEA Coal Information 1989. Coal type assigned according to exporters' data,
United States (EM-522).

Non-OECD Asia:

Hong Kong: ICRCY 89, p. 36.

South Korea: ICRCY 89 Supplement, p. 7. Imports from "other" were assigned to Colombia based on exporter data, (International Coal Report, February 1989, p. 15), and to South Africa according to market shares for January-August 1988 (Coal Statistics Monthly,
November 1988, p. 6).

Taiwan: ICRCY 89, p. 40. Steam coal/metallurgical coal breakout was based on exporters' data for Australia, the United States, and Canada. Exports from South Africa and other countries were assigned to steam coal. 
Other Asia: Exporters' data, United States (EM-522), Australia (ICRCY 88, p. 33), Canada (ICRCY 89, p. 27), U.S.S.R. (Vneshnaya Torgovlya, p. 61), and Indonesia (Foreign Trade Statistics Indonesia Exports 1988). The total for China in IEA Coal Information 1988 was used to estimate Other Asian imports.

\section{Eastem Europe:}

Exporters' data, United States (EM-522), Australia (ICRCY 88, p. 33), Poland (ICRCY 89, p. 30.), U.S.S.R. (Vneshnaya Torgovlya 1989, p. 61), China (IEA Coal Information 1989, p. I.203), West Germany (IEA Coal Information 1989, p. II.198-II.199), and Czechoslovakia (United Nations, Economics and Social Council, Economic Commission for Europe, The Coal Situation in the ECE Region in 1988 and Global Prospects for Coal, August 23, 1989). The steam coal/metallurgical coal breakouts for imports from the U.S.S.R. and Czechoslovakia were assigned.

South America:

Argentina: Exporters' data, United States (EM-522), Australia (ICRCY 88, p. 33), Poland (ICRCY 89, p. 30), Colombia (CNEAF estimate).

Brazil: Importers' data for metallurgical coal (ICR Coal Statistics Monthly, June 15, 1988, p. 15). Exporters' data for steam coal: United States (EM-522), Canada (ICRCY 89, p. 27), and Colombia (CNEAF estimate).

Chile: Exporters' data, United States (EM-522), Canada (ICRCY 89, p. 27) and Australia (ICRCY 88, p. 33).

Mexico: Exporters' data, United States (EM-522).

Other South America: Exporters' data, Colombia (CNEAF estimate).

United States: Monthly Report IM-145.

\section{4.f.ii.C United States Coal Exports and Imports}

Data on US imports and exports is taken direr dy from computer files maintained by the U.S. Department of Commerce, Bureau of the Census, for Monthly Report EM-522. A copy of this information is transferred to the Department of Energy computer center, where it is accessible from the partitioned data sets designated as:

CN6524.PRJ.IMEX.EM522(0)

CN6324.PRJ.IMEX.IM145(0) 
The data contained in these files is not raw transaction data but data that has been aggregated into monthly statistics for the port and coal type in question. This is necessary to maintain the confidentiality of proprietary information that could in some cases be derived from raw transaction data were no aggregations made. In any event, the aggregations have already been made before the data are received by EIA.

\section{4.f.ii.D Prices and Freight Rates}

Both the prices data base and the freight rates data base are derived from the copyrighted Worid Scan section of Coal Week International. The information included in the ICSD data bases are from the last issue for any quarter.

\section{4.f.ii.E Energy Demand}

The principal sources of data for the energy demand data base are:

IEA Countries: Supply and Consumption data, Energy Statistics of OECD Countries 1987 -
1988, (IEA), pps. 78-177.

Non-IEA Countries: Energy Balances data, World Energy Statistics and Balances 1985 1988, (IEA), pps. 144-370.

See also the sources referred to in section 2.4.f.ii.B. Data for years beginning in 1989 and following were derived from electronic data bases maintained by the International Energy Agency in Paris, France. These data bases were used to create the two reports referred to Documentation, (IEA, June 1990)

\subsection{File Management}

\section{5.a Data Security and Confidentiality}

No provisions have been made regarding data security and confidentially as all data in the ICSD are from public sources. However, the US imports and exports data have been aggregated in such a way by the Customs Department that data for an individual shipper may not be discemed from ports having few active shippers.

\section{5.b Forms Level Master Data File Updates}

Please refer to the discussion under section 2.1. 
2.5.c Aggregate Level Master Data File Updates 


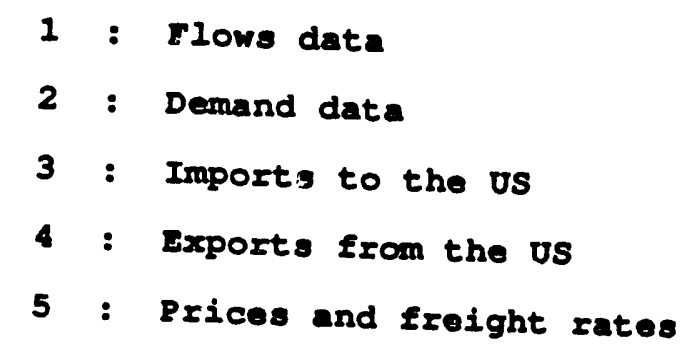

6 : Retนra

: Return to Main Menu

$07 / 05 / 90$

Help $=r 1$

3:54 P.m. (E)

Figure 17. Data Update Menu Display

\section{5.c.i Data Update}

Update of data in the ICSD is controlled by a special update menu choice to automate the process to the extent possible. Data update for the ICSD is not simply a matter of appending requiring special programs to be run that data bases store the same data in different forms, base to the second data base. For the volumes and data added to one version of the data to the volumes1.dbf or demand1.dbf volumes and demand data bases, update must be made records onto the end but by using a specion, as the case may be, not through appending "U," i.e. either UVolume or UDemand). and Freight.dbf, meaning that either the UPrices or UFreight templies to both the Prices.dbf the Imports.dbf and Exports.dbf files there is no UFreight templates should be used. For relatively complicated transformation of do no template, and data update involves a set to an ASCII file and ultimately to a file with use in the ICSD. While most aspects of data up the same structure as the dBase III files in instructions, it may help to look at the source code may be accomplished by the following names are prefaced by "U," e.g. U1.Prg. 


\section{5.c.i.A Updating Volumes.Dbf}

Volumes.dbf contains data on the volume of coal traded between countries or regions by coal type over a number of years. Given the structure of Volumes.dbf, which is organized so that fields are time series years, update would be extremely difficult to accomplish by simple editing of records. Instead, it is preferable to update data in the companion data base, Volumes1.dbf, and then run a special program that transforms its structure into that of Volumes.dbf. In order to protect the integrity of the data in Volumesl.dbf, which, after all, is the only source of the data in the Volumes.dbf, it is recommended that the use of the template file Uvolumes.dbf be used initially. This allows the matrix of importers and exporters to be constructed for each coal type, appended onto Volumes1.dbf, and then used again for a different coal type.

Expressed in dBase code (after dropping to the dBase command interpreter level through Miscellaneous Options), the following commands would work:

USE UVOLUMES

REPLACE ALL TYPE WITH <1 for steam, 2 for met 3 for both $>$

REPLACE ALL YEAR WTTH [198*] <where the correct digit is substituted> EDIT

USE VOLUMES1

APPEND FROM UVOLUMES

USE UVOLUMES

REPLACE ALL TYPE WTTH <next type>

EDIT

USE VOLUMES1

APPEND FROM UVOLUMES

USE UVOLUMES

REPLACE ALL TYPE WTH <last type>

EDIT

USE VOLUMES1

APPEND FROM UVOLUMES

CLOSE ALL

RESUME <to return to ICSD system, once there:> options menu choice 5

miscellaneous menu choice 6 transform volumes 1 to volumes <see below first>

The source of the data is the Energy Information Administration publication, Annual Prospects for World Coal Trade.

\section{5.c.i.B Updating Demand.Dbf}

The most recent version of the ICSD automates the process of updating the Demand1.Dbf (the file used to created Demand.Dbf). 
However, some preprocessing is required since the data supplied by IEA / OECD in Paris is stored in cornpressed format and must be restored to DIF format before it can be included in
the data bases.

The IEA data comes in four forms. The first is individual country data (stored in files as CCCYYYY.DIF, where CCC corresponds to the IEA abbreviation for the country and YYYY are digits corresponding to the first and last years covered by the data, e.g. 8788 . These files contain basic energy statistics data in the metric units appropriate for each of the basic energy types. That is, coal usage will be in metric tons of coal, electricity data will be in GWh, natural gas will be in teracalories, and so forth. However, the user must confirm that the file contains basic energy statistics data, as opposed to energy balance data. The latter is stored in the same file format with the same naming convention except the range of beginning year is different, e.g. 8688. The energy balance data is in tons of oil equivalent. Different ICSD programs accessed through the UDEMAND.PRG are required to deal with the different type
of data.

To complicate matters, the basic field headers are not standard. One type of header file structure is used for OECD countries and another for non-OECD countries. Different update programs must also be used to both build the data files and map the data to Demand1.Dbf. A listing of OECD country codes and whether a country is included in the OECD or not is
found in the ICSD file, Country.Dbf.

The third and fourth file format in use are files named BALccc.DIF and BESccc.DIF. These contain data in tons of oil equivalent (BAL) and metric physical units (BES). These types of files differ from the individual country files in that their field headers are years rather than products. Therefore, still another set of ICSD update programs are required to process them. An additional complication is that both OECD and non-OECD countries are covered by the
files, but there may be substantial differences in product and flow coverage, even to the point
of using different names for the same of using different names for the same product. For instance, coking coal is CKC for non-
OECD countries and COK for OECD countries.

Once one or more of the OECD files are available they must be decompressed using the programs supplied by the IEA for this purpose. The procedure for this is explained by the program. Files should be stored in a separate directory, and the user should record the location chosen as the ICSD update programs require this information.

The update process requires large amounts of computer disk space. Approximately 3 megabytes are required for the compressed IEA / OECD files, 5 megabytes for the fecompressed DIF versions of the files, and approximately 3 megabytes of working storage for the ICSD update files created during the process.

Before running the demand choice from the update menu, the file UDEMAND.PRG should be edited using an ASCII editor to select those programs required for the type of files made available by the IEA. The file contains an explanation of which type of ICSD program is 
required for each data type. Unnecessary programs should be commented out of the calling sequence by placing an asterisk before the relevant line. The final program, used to convert Demand1.Dbf to Demand.Dbf, and reindex it, should not be commented out, as it must be run whenever data in Demand1.Dbf are changed.

Manual update is also possible by using the Demand1.Dbf and the dBase Browse command from the dot prompt. Manual update for a new year is also possible using a process very similar to that described at length for the update of Volumes.dbf:

USE UDEMAND

REPLACE ALL TYPE WTIH <1 for steam, 2 for met 3 for both $>$

REPLACE ALL YEAR WTHH [198*] <where the correct digit is substituted>

EDIT

USE DEMAND1

APPEND FROM UDEMAND

CLOSE ALL

RESUME <to retum to ICSD system, once there:>

options menu choice 5

miscellaneous menu choice 6

transform demand 1 to demand <see below first

\section{5.c.i.C Updating Prices.Dbf and Freight.Dbf}

All data on freight rates are stored in Freight.dbf, while data on prices are kept in Prices.dbf. The source for both types of data is the private commercial publication Coal Week International from McGraw-Hill. The two data bases are prepared from information published in the portion of each issue known as "World Scan." The data used is from the last issue published in each quarter.

There are two methods of updating the data: (a) using a written copy of the document and manually entering the data into a special update templates controlled by Update.Prg; or (b) by using NEXIS to download the data into an ASCII file, and by editing the result using Lotus 1-2-3's Data Parse and Translate functions to create a new dBase III file that may then be appended to either the Freight or Prices data bases. The latter procedure is relatively complex and is probably the suitable choice only when many issues have to be input at once.

\section{Using the Update Program}

From the update menu select choice 5, Prices and Freight rates. This will cause a second program to control user access to the templates and data files for the update. This procedure allows the data structure in a typical freight rate section of "World Scan" to be entered in to a template which is then added to the master file. Of course, the utility of the template depends on whether the publishers provided the same information for the same countries of origin and 
destination as are stored in the template. There have often been significant format and coverage changes between issues and the entire structure is reworked from time to time. For purposes of the ICSD it is important to keep data in its current data base format to the greatest extent possible. Some of the conventions that may apply are:

\section{Capitalize all entries}

When only one rate is specified, enter it in both the Hibound and Lowbound fields

When no port of origin or no destination is specified, enter $\mathbf{N} / A$

Some data entry functions can be simplified using the dBase menu structure invoked from CTRL+HOME. Specifically, it may be useful to "lock" the first column and then use CTRL+Kight Arrow to enter data in the low and high price fields.

\section{Parsing ASCII Files}

Updating the data base using downloaded ASCII files from NEXIS involves multiple steps:

Load the NEXIS ASCII files (the results from an on-line query of the Coal Week International end of quarter issues) into Lotus using the File Import Text function.

Use the Lotus Data Parse function to divide the text into columns of the appropriate size. The column headings (field names) should be the same as those used in data base is being updated. It is recommended that immediately beneath the field names, a row of dummy characters be inserted rather than the first row of actual data. This makes it easier for the Lotus Translate utility to create the proper sized dBase III file. For example (only a few fields are given):

ORIGIN

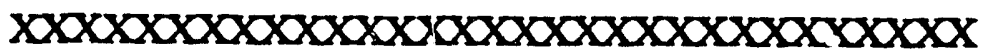

These dummy entries also indicate what type of variable is involved; that is, whether a character, date or numeric field is being used. The Lotus Data Parse guideline should also be based on the dummy line rather than the first line of data as this will produce columns of the right width.

After parsing the data, a date should be added to each line under the ISSUEDATE column. This should be done with the Lotus date entry function rather than copying the text date. Non-data lines from the original text should be removed. The best way to do this is to use the Lotus Worksheet Delete Row command in a macro. 
Some clean-up of the data may be required. Since each row should be a distinct and comprehensible record on its own, the CWI practice of not repeating the names of countries of origin, ports or destinations when they are the same as the previous entry must be compensated for by using a Lotus macro to copy the information. The same applies to the CWI practice of continuing some entries onto second lines.

Mark the range containing the edited data, save the file, and use the Lotus Translate program to create a dBase III file. Some additional manipulation of the resulting $\mathrm{dB}$ ase file may be required, including filing the $\mathrm{M1}, \mathrm{D1}$ and $\mathrm{Y} 1$ fields from the date information. It may also be desirable to use dBase data editing functions to separate originating country from originating port, if this step was not done while in Lotus.

Once the user-created $\mathrm{dB}$ ase file has been edited, use the $\mathrm{dBase}$ Append command to add the new entries to the data base as explained above. Remember to reindex.

\section{5.c.i.D Updating the Exports and Imports Data base}

The Exports and Imports data bases each contain records produced from transaction data kept by the Bureau of the Census. Computer files containing this data are used by the Energy Information Administration to prepare special reports on the level of coal import and export transactions. These data are stored in the EIA computer system in two partitioned data sets designated as:

$$
\begin{aligned}
& \text { CN6524.PRJ.EM522.IMEX(0) } \\
& \text { CN6524.PRJ.IM145.IMEX(0) }
\end{aligned}
$$

The data contained in these files is not raw transaction data but data that has been aggregated into monthly statistics for the port and coal type in question. This is necessary to maintain the confidentiality of proprietary information that could in some cases be derived from raw transaction data where no aggregations were made. Consult the documentation stored in related files for the same project for additional information on record layout, screening procedure, and so forth.

Update for purposes of the ICSD requires the following steps:

a. Editing the Original Data Set Both the imports and exports data base may be edited prior to downloading, to reduce the length of time required to produce a microcomputer version of the file. Refer to the record layout for each file. The final structure of the file used by the ICSD does not require all of the information used contained in each mainframe record. For instance, the Census Bureau assigns a commodity key in columns 1-7. Since this code is the same for each record in the data base (i.e. all records are about coal transactions), it is not necessary to add to the size of an already large file with the information. The record length of the mainframe 
partitioned data sets varies and is longer for the imports file than exports. The update program allows for the difference in record length.

b. Downloading The actual process of downloading depends on the user's communication software. Almost all programs allow information to be stored in a file. The process is to tum on this feature after using the SuperWylbur List command to display all records in the original base file as edited. This may take several hours, depending on the communications baud rate. The result is two large files on the user's hard disk- one for exports and one for imports.

For instance, to download the files using EIA's Arbiter system on the local area network, the user would (a) sign on to Arbiter; (b) select the second choice from the main Arbiter menu, File Transfers; (c) hit the F10 key to select file transfers; (d) use the TEXT transfer from the specified mainframe files, advising Arbiter to put the transferred file in either C:VCSDVMPORTS.TXT or C:VCSDVEXPORTS.TXT, depending on which file was being downloaded; and (e) then exiting from the Arbiter system via the esonpe key and then selecting the last choice, Signoff, from the menu with the F10 key. Note that the Arbiter drivers must be removed and the system rebooted without them (to restore the full complement of memory) in order to retum to the ICSD.

c. Capturing the Downloaded Data in a DBF file The first step of capturing the downloaded ASCII files into dBase .dbf file format is to create a .dbf file with a character field of 80 bytes. Either the UExports.dbf or UImports.dbf file structures will do. With this data base in use, the dBase command APPEND FROM is entered with the parameter TYPE SDF. This will capture the records in the single field. Once finished, it is necessary to modify the structure of the dara base to add those fields used by the imports and exports data base, as the case may be. For instance, add the following fields of the specified type and size to the special update data base:

\begin{tabular}{llll} 
Field Name & Type & Width & Dec \\
\cline { 2 - 3 } EXPRTS & Character & 80 & \\
TYPE & Numeric & 2 & 0 \\
COUNTRYCOD & Numeric & 3 & 0 \\
PORTCODE & Numeric & 2 & 0 \\
MONTH & Numeric & 2 & 0 \\
YEAR & Numeric & 2 & 0 \\
RECCOUNT & Numeric & 1 & 0 \\
EXPORTCODE & Numeric & 1 & 0 \\
QUANTITY & Numeric & 12 & 2 \\
VALUE & Numeric & 11 & 2 \\
PRICEPERTN & Numeric & 11 & 2 \\
DATE & Date & 8 & \\
ICSDTYPE & Numeric & 1 & 0
\end{tabular}




$\begin{array}{llll}\text { ICSDREG } & \text { Numeric } & 1 & 0 \\ \text { ICSDPORT } & \text { Numeric } & 1 & 0\end{array}$

d. Replacing.DBF Fields Once the data bases have been constructed and the large field filled, the process of filling the new fields with information from the 80-byte field begins. This is done by assigning a variable with the text or number (actually, with the positions these values may occupy) to be used to fill a given field. Usually, this would be done with the dBase Substr function. Note that where the field to be filled is numerical, the dBase Val function must be used as well. Once the appropriate variable has been created, the dBase Replace command may be used to actually put the new data in the field for each record. Note also that the EIA compiter may have inserted an extra character, $\Delta$, into the first position in the large field. If so this must be removed using a command such as REPLACE ALL EXPORTS WITH SUBSTR(EXPORTS,2,80). This should be done before other editing. For fields beginning with ICSD, the U7.Prg, described below, must be run.

The following dBase code, contained in U4.Prg, provides a basis for the process. If desired, the file could be slightly modified for use in the update process and run. A similar program for updating the Imports.dbf is contained in U5.prg.

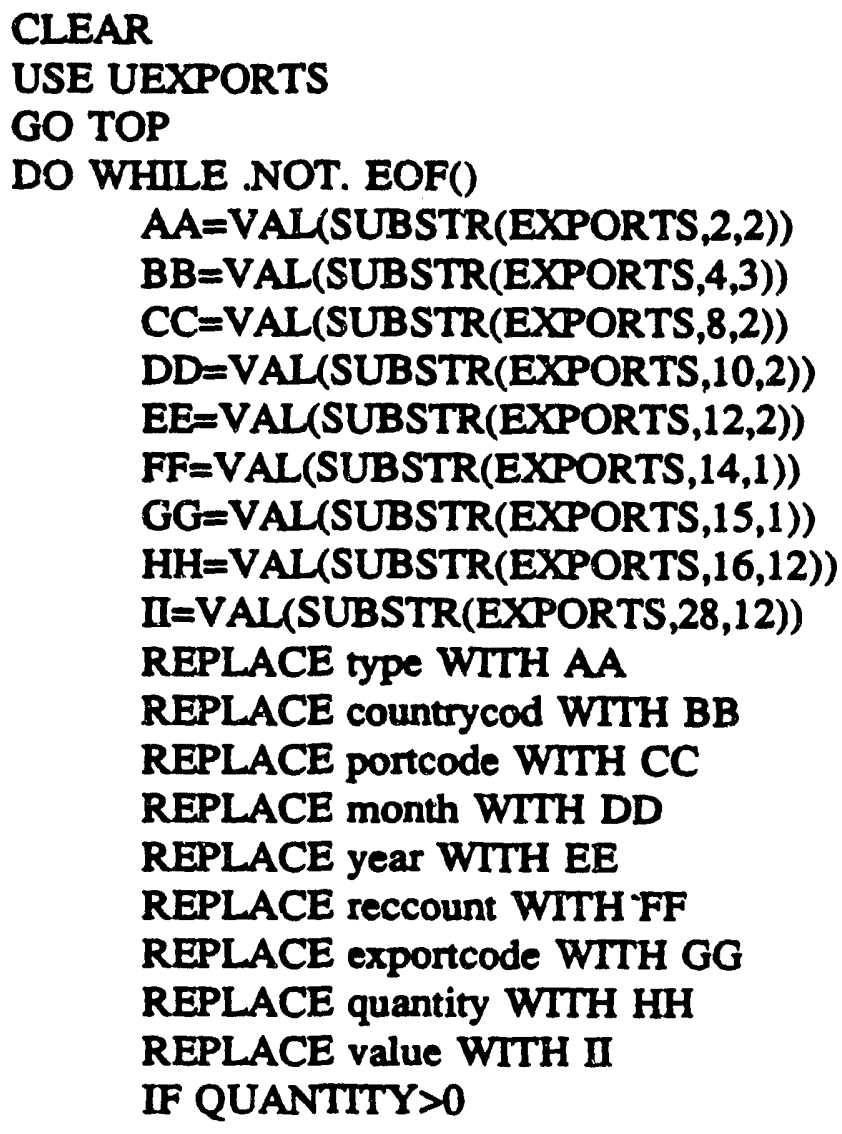




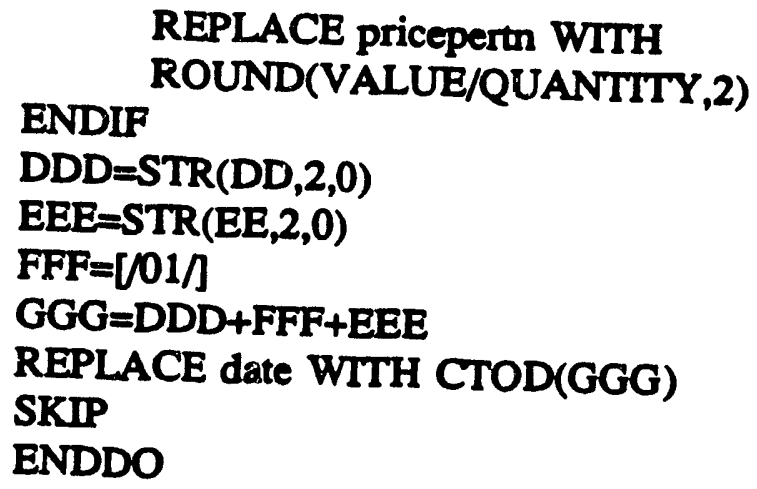

The code above is only illustrative. Compound replace statements have been avoided for clarity, but would probably be used to save time. The exact beginning and ending points for variables such as AA would depend on the record layout of the original mainframe file, reproduced in the Program Maintenarice Manual. Where the wherever exports

e. Append to ICSD Original [Review step $f$ before taking this step] After the correct data has been placed in each field of the UExports.dbf / UImports.dbf, the structure be). Then the following to dele the long field (either exports or imports, as the case may

\section{USE EXPORTS}

\section{APPEND FROM UEXPORTS}

Here again substitute imports for exports when that file is being updated.

f. Run the Abbreviation Substitution Program. U7.Prg The ourpose of U7 is to replace those fields designated ICSD with the appropriate code. This program may take one and a half hours to run, since it operates on the entire imports and exports data bases. However, it may be modified so the data bases in use are UExports.dbf and UImports.dbf, in which case it should be run before the previous step of
appending to the original.

8. Modify Calling Program Code, E2.Prg and E3.Prg A minor modification must be made to the program code of the main calling programs that use the imports and exports data bases. This may be done by any word-processor capable of writing pure other program tho not use either the built-in dBase Modi Comm word processor or any program code is simple. First usen-ASCII format. The actual modification of the UPDATE NOTES comment to the word processor's search facility to find the year variable with the numbers that rogram code. Then modify the second month and contained in the data base. 
h. Resort and Reindex the Two Data bases Since the structured query depends on specific indexing procedures on a pre-sorted index, the final step is to sort the file to a new file name, close all files, copy the new name to the original name and reindex. Reindexing may be accomplished by running the File Maintenance choice from the Options menu, but this will not resort. So, before reindexing, use the following code:

SET TALK ON

USE EXPORTS

SORT ON DATE,ICSDTYPE,COUNTRYCOD,ICSDPORT TO EXPORTS1

CLEAR ALL

RUN COPY EXPORTS1.DBF EXPORTS.DBF

RUN DEL EXPORTS1.DBF

USE IMPORTS

SORT ON DATE,ICSDTYPE,COUNTRYCOD TO IMPORTS1

CLEAR ALL

RUN COPY IMPORTS1.DBF IMPORTS.DBF

RUN DEL IMPORTS1.DBF

SET TALK OFF

(if reindexing is desired:)

USE EXPORTS

INDEX ON STR(ICSDTYPE,1,0) + STR(YEAR,2,0) + STR(ICSDREG,1,0) + STR(ICSDPORT, 2,0) TO E2A

INDEX ON STR(ICSDTYPE,1,0) + STR(COUNTRYCOD,3,0) +;

STR(ICSDPORT,2,0) TO E2B

USE IMPORTS

INDEX ON STR(ICSDTYPE,1,0) + STR(YEAR 2,0)+STR(ICSDREG,1,0) TO E3A

INDEX ON STR(ICSDTYPE,1,0) + STR(YEAR,2,0) + STR(COUNTRYCOD,3,0) TO E3B CLEAR ALL

The steps outlined above apply to the modification of the other data base as well.

That is, if they were just used to update Exports.dbf, the same procedure is run again with appropriate changes noted above, for Imports.dbf.

2.5.d Procedures to Declare Data "Final" for a Given Cycle 
After all data updates have been completed, it is necessary to run Option 4, Index Maintenance, a final time to ensure that none of the required index files have been corrupted. Data update is then complete. The intermediate files used in the update, such as all files ending in DIF can be erased. (These files were created by the IEA / OECD file decompression program referred to 2.5.c.i.B).

The team leader or the ICSD project leader declares the data final after the Annual Prospects for World Coal Trade publication has been signed by the EIA Administrator.

\section{5.e Data Revisions}

Single data revisions may be made directly into the affected data base using the dBase Browse command. However, if made in the Volumes1.Dbf or Demand1.Dbf (which should be updated rather thar: their unnumbered counterparts, Volumes.Dbf and Demand.Dbf), the update menu should be used to sun the final structural conversion program. Any other revisions require the update procedures identified in section 2.5 .

Major data revisions are made once a year and on an as-needed basis if new data becomes available, in compliance with EIA Standard 88-05-02, Publication of Revisions.

\section{5.f Survey Performance Statistics}

Please refer to the discussion in section 2.1.

\section{5.g Master File Backup and Archiving Procedures}

After all updates have been completed, the new files should be copied into the backup directory using the DOS command COPY *.DBF x: backupdir. The special backup utility - U1.PRG should be run from the dBase prompt (see Miscellaneous Options) to mark each of the revised files as the final edition.

In order to create an archive of any ICSD files, whether earlier versions of key files, the previous set of backed-up files, or whatever, the following DOS commands should be used from inside the directory holding ICSD files, after formatting several blank diskettes:

\section{BACKUP c: a:}

This will cause DOS to copy all files to storage diskettes. These should be numbered sequentially, with a notation made of the date of the backup. To restore the archive use the DOS command: 


\section{RESTORE a: c:}

Where a: and c: are the locations of the archived files and the drive holding the ICSD files, respectively. This will cause the archived files to permanently overwrite the existing files.

As the ICSD is not resident on the EIA mainframe, the only archive procedure is the need to keep a set of the floppy diskettes with ICSD files. 

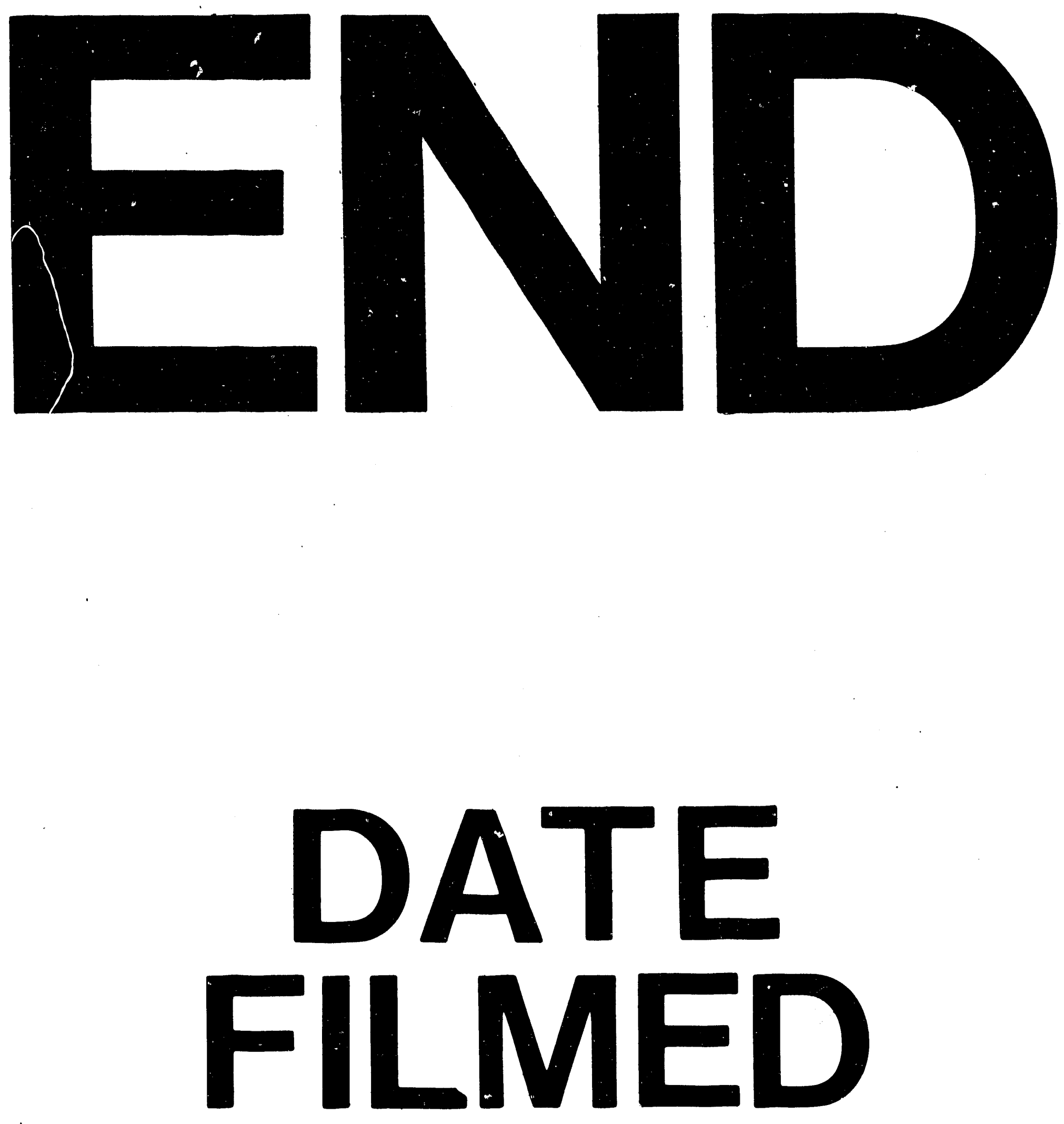

1

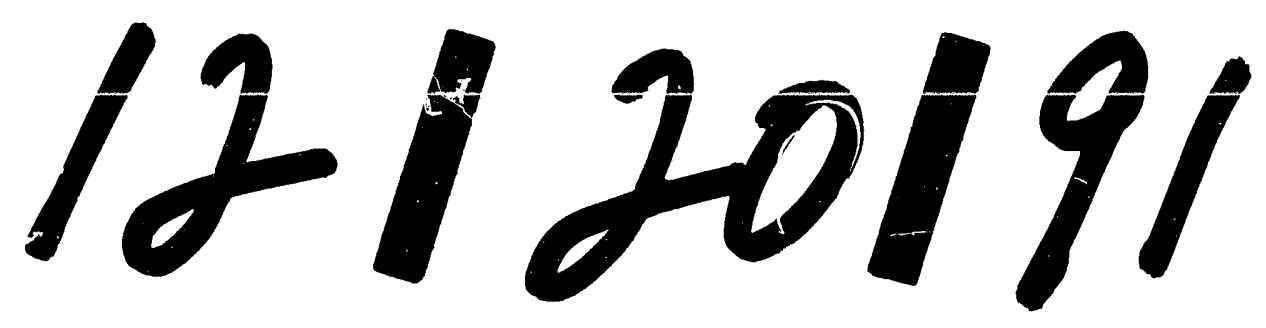


